Research review paper

\title{
Ashbya gossypii beyond industrial riboflavin production: A historical perspective and emerging biotechnological applications
}

\author{
Tatiana Q. Aguiar ${ }^{1}$, Rui Silva ${ }^{1}$, Lucília Domingues * \\ CEB - Centre of Biological Engineering, University of Minho, 4710-057 Braga, Portugal
}

\section{A R T I C L E I N F O}

\section{Article history:}

Received 28 May 2015

Received in revised form 28 September 2015

Accepted 4 October 2015

Available online $\mathrm{xxxx}$

\section{Keywords:}

Ashbya gossypii

Physiology

Metabolism

Genetic engineering

Riboflavin

Recombinant proteins

Single cell oil

Flavour compounds

\begin{abstract}
A B S T R A C T
The filamentous fungus Ashbya gossypii has been safely and successfully used for more than two decades in the commercial production of riboflavin (vitamin $\mathrm{B}_{2}$ ). Its industrial relevance combined with its high genetic similarity with Saccharomyces cerevisiae together promoted the accumulation of fundamental knowledge that has been efficiently converted into a significant molecular and in silico toolbox for its genetic engineering. This synergy has enabled a directed and sustained exploitation of A. gossypii as an industrial riboflavin producer. Although there is still room for optimizing riboflavin production, the recent years have seen an abundant advance in the exploration of A. gossypii for other biotechnological applications, such as the production of recombinant proteins, single cell oil and flavour compounds. Here, we will address the biotechnological potential of A. gossypii beyond riboflavin production by presenting (a) a physiological and metabolic perspective over this fungus; (b) the molecular toolbox available for its manipulation; and (c) commercial and emerging biotechnological applications for this industrially important fungus, together with the approaches adopted for its engineering.
\end{abstract}

(c) 2015 Elsevier Inc. All rights reserved.

\section{Contents}

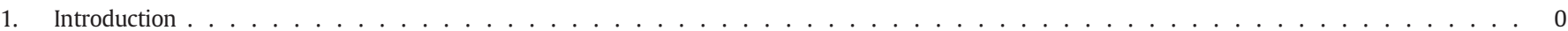

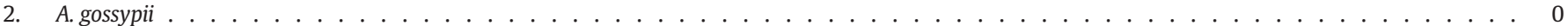

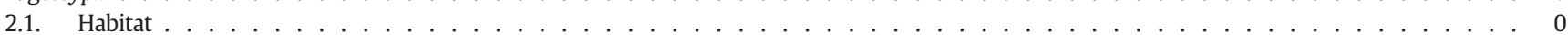

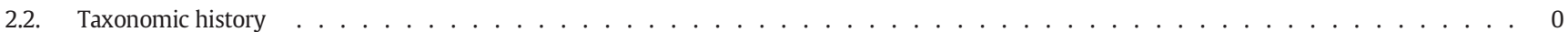

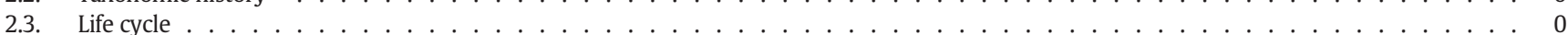

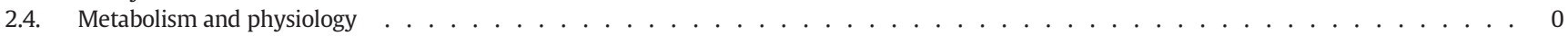

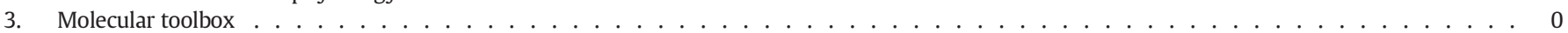

4. Commercial and emerging biotechnological applications . . . . . . . . . . . . . . . . . . . . . . . . . . . . . . . . . . . . . . . 0

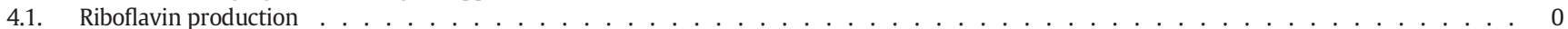

4.2. Recombinant protein production . . . . . . . . . . . . . . . . . . . . . . . . . . . . . 0

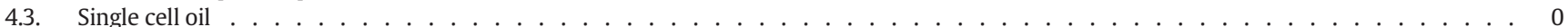

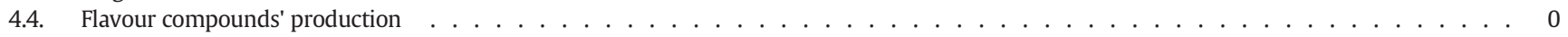

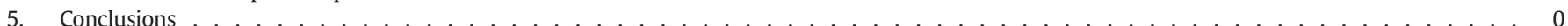

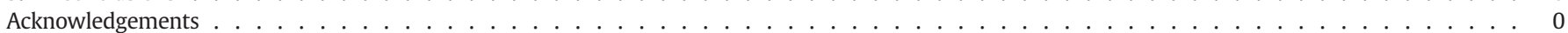

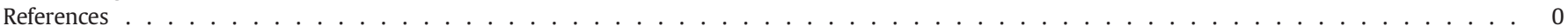

* Corresponding author.

E-mail addresses: tatiana.aguiar@deb.uminho.pt (T.Q. Aguiar), rsilva@ceb.uminho.pt (R. Silva), luciliad@deb.uminho.pt (L. Domingues).

1 These authors contributed equally to this work

\section{Introduction}

The filamentous hemiascomycete Ashbya gossypii (syn. Eremothecium gossypii) has recently emerged as an attractive cell factory to produce yet unexplored high-value products. Industrially exploited for more than 20 years due to its natural ability to overproduce riboflavin, A. gossypii is considered a remarkable example of the sustainable White Biotechnology 
business model (Kato and Park, 2012; Lim et al., 2001; Stahmann et al., 2000; zu Berstenhorst et al., 2009). Nevertheless, the scientific prominence of $A$. gossypii is not limited to its biotechnological potential, since it is also extensively used as a model organism in fungal developmental and evolutionary biology studies (Perez-Nadales et al., 2014; Schmitz and Philippsen, 2011; Wendland and Walther, 2005). Its industrial relevance and the basic knowledge accumulated along the years promoted the development of molecular and in silico tools that, in turn, have allowed the continuous engineering of A. gossypii strains with improved riboflavin production traits, either through random or rational approaches.

The overwhelming capacity of A. gossypii to produce riboflavin will continue to be targeted for optimization, even more with the advent of systems biology. However, since the beginning of this decade, we have witnessed the increasingly stronger shift of the A. gossypii biotechnological paradigm from riboflavin to other commercially interesting high-value compounds, such as recombinant proteins (Ribeiro et al., 2010), single cell oil (SCO; Ledesma-Amaro et al., 2014a) and flavour compounds (Ravasio et al., 2014; Ledesma-Amaro et al., 2015). In this review, we will focus on the emerging biotechnological potential of this promising cell factory that nowadays goes far beyond riboflavin production (Fig. 1). This review will first provide a historical perspective over this fungus, highlighting its relevant metabolic and physiological traits (Section 2). Subsequently, the molecular toolbox established and available for A. gossypii manipulation will be presented (Section 3) and the random and rational genetic engineering approaches that have been used in the context of riboflavin, recombinant protein, SCO and flavour compounds' production will be described (Section 4). We will conclude by presenting future challenges and directions that should be taken in order to guide these emerging biotechnological applications through the successful track of riboflavin production.

\section{A. gossypii}

\subsection{Habitat}

A. gossypii was originally isolated from infected cotton bolls (Gossypium sp.) harvested in the British West Indies (Caribbean region) and identified as one of the causative agents of stigmatomycosis (Ashby and Nowell, 1926). Subsequently, A. gossypii strains were also isolated from other crops widespread along the tropic and sub-tropic regions

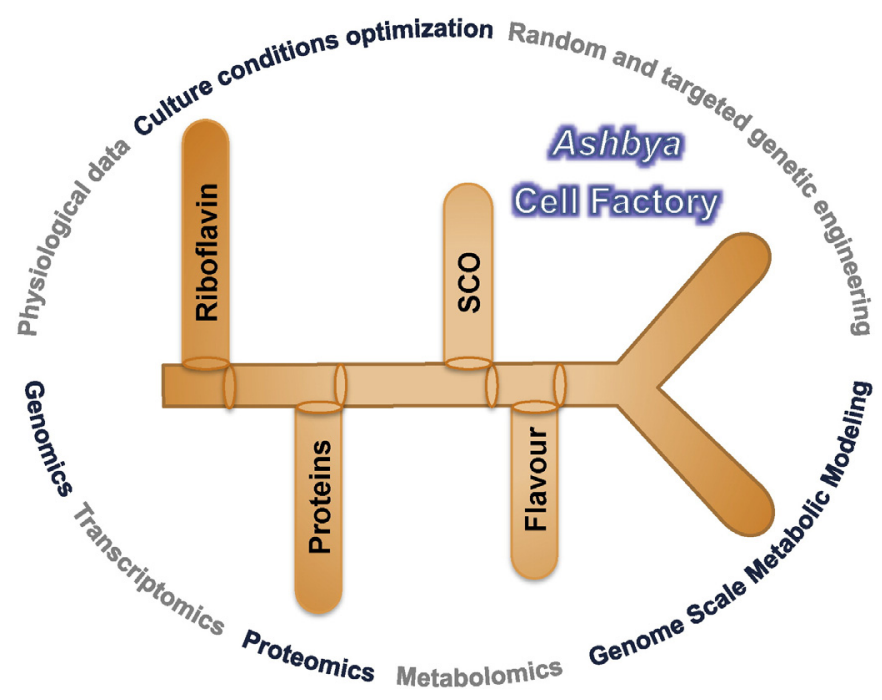

Fig. 1. A. gossypii's biotechnological applications. Following its established industrial use in riboflavin production, emerging biotechnological applications for this fungus are: recombinant protein, single-cell oil (SCO) and flavour compounds' production. The technological approaches used for the development of these biotechnological applications are presented in the closing circle. of Northern America, Southern America and South Africa, such as coffee, citrus fruits and tomatoes (Batra, 1973; Pridham and Raper, 1950). More recently, A. gossypii was isolated from large milkweed bugs found feeding on oleander in Florida, USA (Dietrich et al., 2013). Insect vectors, predominantly those with pierce-sucking mouthparts such as the Heteroptera, are essential for the transmission of this fungus, as the fungus itself is unable to penetrate the outer cells of healthy fruits and seeds unless a mechanical injury occurs (Batra, 1973; Pridham and Raper, 1950). Since the most important mode of infection requires insects to transport and inject spores or mycelial fragments into the tissue of the plant (Batra, 1973; Pridham and Raper, 1950), the control of the insect population by insecticides has proven efficient in preventing the dissemination of A. gossypii (Dammer and Ravelo, 1990).

The characteristics of the plant tissues where A. gossypii has been found (rich in readily usable sugars and/or oils; Caskey and Gallup, 1931) and its insect-dependent infection mode justify modest secretion of extracellular enzymes by A. gossypii (Aguiar et al., 2014a; Ribeiro et al., 2010), as its proliferation does not depend on the degradation of complex substrates. On the other hand, the A. gossypii's need to attract insects for spreading benefits from its capacity to produce large amounts of strong volatile aromas (Ravasio et al., 2014; Wendland et al., 2011). Interestingly, this close relationship between A. gossypii and certain plant-feeding insects has also provided some hints regarding its riboflavin overproduction capacity (Dietrich et al., 2013; Walther and Wendland, 2012). It has been hypothesised that the overproduction of riboflavin constitutes an ecological advantage for both the fungus and insects in their natural niches, by conferring them protection against some plant defences (Walther and Wendland, 2012; Dietrich et al., 2013). Therefore, a better understanding of the existing biological relationship between $A$. gossypii and its insect vectors holds the potential to unravel new perspectives and opportunities for biotechnology, such as the development of environmentally-friendly insecticides.

\subsection{Taxonomic history}

A. gossypii was first characterized in 1926 by Ashby and Nowell (Ashby and Nowell, 1926), who at the time named it Nematospora gossypii, based on the close resemblance of its sporangia and spores to those of other Nematospora species. In 1928, based on cytological and phylogenetic studies, Guilliermond (1928) placed this species in the class Hemiascomycetes and assigned to it a new genus name, Ashbya, because in contrast to other Nematospora species it grew exclusively in a mycelial form and polynucleated cells were in the origin of its sporangia. Fragoso and Ciferri (1928) considered this species to belong to the order Saccharomycetales (Endomycetales) and also suggested separating it from the Nematospora genus, presenting a Latin description for it under the generic name Ashbia.

As this species appears to possess characteristics of several families, further classification attempts differed along the years. Ascospore morphology (needle-shaped with a whiplike filament at one end) and the presence of hyphal growth were considered to separate the genus Ashbya, at least at the family level, from yeast genera belonging to the Saccharomycetales (von Arx and van der Walt, 1987). However, the close relationship between A. gossypii and Saccharomyces cerevisiae started to became obvious when the sequence analysis of the first set of clones of A. gossypii genomic DNA (gDNA) revealed an unpredictably high degree of synteny to the gene order of their homologues in S. cerevisiae (Altmann-Jöhl and Philippsen, 1996; Steiner and Philippsen, 1994). Based on phylogenetic analysis of ribosomal DNA (rDNA) sequence divergence, Kurtzman (1995) placed the genera Ashbya, Eremothecium, Holleya and Nematospora in a single genus, Eremothecium, and introduced the family Eremotheciaceae for this genus. Prillinger et al.'s (1997) data on cell wall sugar composition, dityrosine content in ascospores, ubiquinone side chains and sequence analysis of the genes coding for the $18 \mathrm{~S}$ rDNA and ITS region supported 
the inclusion of these genera within a single genus, as proposed by Kurtzman (1995), but within the Saccharomycetaceae family.

The sequencing and annotation of the A. gossypii genome finally elucidated the close relation between $A$. gossypii and $S$. cerevisiae, revealing homologues in S. cerevisiae for $94 \%$ of the 4776 annotated proteincoding genes of A. gossypii, $90 \%$ of which at syntenic positions (Brachat et al., 2003; Dietrich et al., 2004, 2013). Only 6\% of the A. gossypii's protein-coding genes have no homologue in S. cerevisiae, but most of these genes have a syntenic homologue in other closely related species (Dietrich et al., 2004, 2013; Wendland et al., 2011; Wendland and Walther, 2014). The small size (9.12 Mb) and organization of the A. gossypii's genome into only seven chromosomes also provided compelling evidence for an ancient whole-genome duplication (WGD) of the Saccharomyces lineage after its split from the Ashbya lineage (Dietrich et al., 2004). With the genome sequence of several fungal species available, fungal phylogenomic studies have been conducted (Fitzpatrick et al., 2006; Wang et al., 2009), congruently placing A. gossypii in the order Saccharomycetales, close to other pre-WGD species, like Kluyveromyces lactis, Kluyveromyces waltii and Saccharomyces kluyveri. However, the monophyly of these four species is still unsettled (Wang et al., 2009). Kurtzman and Robnett (2003) suggested that these species are paraphyletic, assigning the genus Eremothecium to the clade 12 of the Saccharomyces complex, K. lactis to the clade 11 and $K$. waltii and $S$. kluyveri to the clade 10 . In contrast, other studies suggest that the four species are monophyletic, constituting themselves a clade (Fitzpatrick et al., 2006; Wang et al., 2009).

\subsection{Life cycle}

A. gossypii is one of the simplest filamentous fungal species studied, which due to its close relationship to yeast, small genome size and easy genetic manipulation arose as an attractive model to study fungal developmental biology (reviewed in Perez-Nadales et al., 2014; Schmitz and Philippsen, 2011; Wendland and Walther, 2005). Its life cycle (Fig. 2) starts with a short period of isotropic growth that initiates the germination of its uninucleate haploid spores and leads to the formation of a spherical germ bubble at the centre of the spores, which is where the nucleous is positioned (Alberti-Segui et al., 2001; Wendland and Philippsen, 2000). Then, actin patches start to accumulate in a region of the germ bubble cortex perpendicular to the axis defined by the spore needle, marking the emergence of the first germ tube and the switch to polarized growth (Knechtle et al., 2003). The tip of the germ

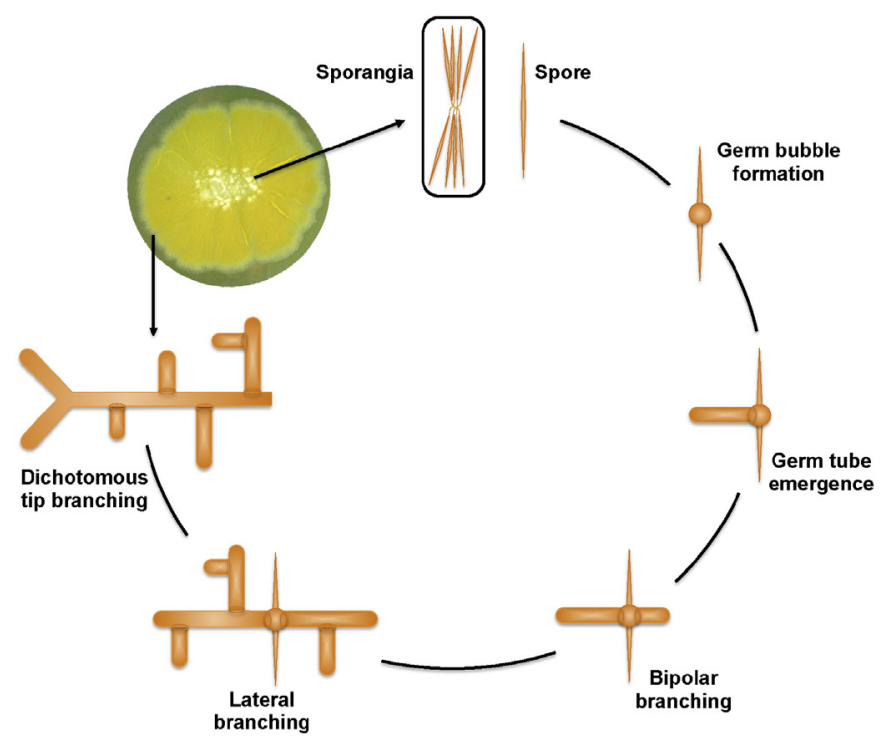

Fig. 2. Schematic representation of the A. gossypii life cycle. The colony photo represents growth for eight days on agar-solidified complex medium. tube continues extending and an actin ring at the neck between the germ bubble and the first germ tube initiates the formation of the first septum (Knechtle et al., 2003). Septation and nuclear division are uncoupled events in A. gossypii, and thus each hyphal compartment encloses multiple nuclei (Kaufmann and Philippsen, 2009; Wendland and Philippsen, 2000). These exhibit asynchronous division cycles and variable ploidy, despite sharing a common cytoplasm (Anderson et al., 2015; Gladfelter et al., 2006). At the opposite side of the germ bubble a second germ tube is formed, giving rise to a bipolar germling (Wendland and Philippsen, 2000). From these initial hyphae a young mycelium is generated by lateral branching. Hyphal tip growth speed increases during maturation and concomitantly hyphal tips start to undergo dichotomous branching, leading to the formation of Y-shaped hyphal filaments (Ayad-Durieux et al., 2000). To deal with the high demand for novel cell surface at the growing tip, secretory vesicles containing new membrane and cell wall components are transported along the actin cytoskeleton to the tip of fast-growing hyphae, where they accumulate in Spitzenkörper-like spherical structures and fuse with the plasma membrane, releasing their content to the extracellular space (Köhli et al., 2008). The secretion of proteins required for cell wall synthesis and lysis of substrates is thus thought to occur preferentially (although not exclusively) at the hyphal tip (Read, 2011).

The vegetative growth of $A$. gossypii ceases upon nutrient limitation and old mycelia eventually enter the sporulation phase, event that is linked with the production of riboflavin (vitamin $B_{2}$ ), which dramatically increases during this phase (Stahmann et al., 2001). However, riboflavin production is not exclusively connected to sporulation, as non-sporulating mycelia also accumulate riboflavin (Walther and Wendland, 2012). Old hyphae fragment at septal sites to form sporangia that usually contain eight endospores bound together by filaments, which are set free by lysis of the sporangia cell walls (Wendland and Walther, 2005). On solid media, the sporulation zone is rich in strongly aggregated hyphae that rise above the agar and form synnemata-like structures (Grünler et al., 2010). In liquid media, old mycelia undergo autolysis during the latest phase of its life cycle (Pridham and Raper, 1950).

Sporulation in A. gossypii is affected by the mitogen-activated protein (MAP)-kinase pathway that governs the mating pheromone response and the starvation/filamentous growth response, and by the cyclic adenosine monophosphate/protein kinase A (cAMP/PKA) pathway that governs all aspects of cell physiology, particularly morphogenesis, growth and sporulation (Wasserstrom et al., 2013, 2015; Wendland et al., 2011). However, the specific mechanisms of spore formation in A. gossypii are still poorly understood, not being clear whether there is a meiotic component to sporulation (Wasserstrom et al., 2013, 2015). The A. gossypii reference strain ATCC10895 was found to harbour four identical mating-type cassettes in its genome containing MATa information, but no MAT $\alpha$ orthologs were found (Dietrich et al., 2013; Wendland et al., 2011), which led to question the existence of a sexual cycle in this fungus (Wendland et al., 2011). However, the recent genome sequencing of a new A. gossypii strain (FDAG1) isolated from large milkweed bugs revealed that this wild isolate encodes both MATa and MAT $\alpha$ sequences, suggesting that some A. gossypii strains likely have a sexual cycle (Dietrich et al., 2013).

\subsection{Metabolism and physiology}

A. gossypii is a natural overproducer of riboflavin (vitamin $B_{2}$ ), which confers to its mycelia a characteristic yellow colour (Wickerham et al., 1946). Overproduction of this vitamin in A. gossypii is known to start at the stationary phase, when the growth rate declines, concomitantly with sporulation (Karos et al., 2004; Stahmann et al., 2001). As a rule, similar kinetics of production have been seen during microbial synthesis of secondary metabolites, but not primary metabolites. Therefore, 
riboflavin is considered in A. gossypii as a pseudo-secondary metabolite (Schlösser et al., 2001).

Riboflavin is synthesized de novo from guanosine-5-triphosphate (GTP) and ribulose 5-phosohate (ribulose 5-P) through a multi-step pathway controlled by six RIB genes (Fig. 3) (Karos et al., 2004). The riboflavin production phase is characterized by a strong increase in the expression of three of these genes (AgRIB3, AgRIB4, and AgRIB5), which are regulated at the transcription level (Schlösser et al., 2001, 2007; Walther and Wendland, 2012). Overproduction of riboflavin by A. gossypii has been shown to be triggered by environmental stresses, such as nutritional and oxidative stress (Kavitha and Chandra, 2009, 2014; Silva et al., 2015; Schlösser et al., 2007; Walther and Wendland, 2012). Alongside with the induction of riboflavin overproduction and secretion, oxidative stress has been shown to also induce the activity of enzymes that are involved in the detoxification of reactive oxygen species (ROS), e.g. catalase and superoxide dismutase (Kavitha and Chandra, 2009, 2014). Hence, the secretion of large amounts of riboflavin by A. gossypii was suggested to function as a possible stress defence mechanism against the ROS produced by plant defences (Walther and Wendland, 2012). The AgYap1p, a transcription factor that plays a major role in directing the cellular responses to various stresses, was shown to regulate the expression of the AgRIB4 gene and to mediate an AgYap1p-dependent increase in riboflavin production during oxidative stress (Walther and Wendland, 2012). AgYap1p also seems to regulate the expression of $A g R I B 3$ and $A g G S H 1$ (gene encoding $\gamma$ glutamyl cysteinyl synthase, a rate-limiting enzyme in the biosynthesis of glutathione - molecule involved in the A. gossypii antioxidant defence), both of which have been shown to be up-regulated in response to oxidative stress (Kavitha and Chandra, 2014). These evidences show that riboflavin overproduction by A. gossypii is related with regulatory mechanisms rather than with metabolic capabilities. Indeed, comparatively with its close relatives $S$. cerevisiae and $K$. lactis that do not overproduce riboflavin, A. gossypii does not possess exclusive enzymes directly involved in the riboflavin biosynthetic pathway that could explain its overproducing trait (Gomes et al., 2014). On the other hand, significant differences exist at the intergenic level between A. gossypii and its non-flavinogenic relatives (Brachat et al., 2003; Wendland et al., 2011), which hints at the existence of regulatory differences between them.

The first physiological studies focusing on the influence of some common environmental factors on the A. gossypii's growth started to appear in the literature as a reflection of the eventual interest in using this fungus for industrial applications. As early as 1930, Farries and Bell (1930) noted the production of a yellow pigment (riboflavin) by certain A. gossypii strains when investigating the nitrogen requirements of this species. In their study, potassium nitrate and ammonium salts were not utilized as nitrogen sources, observations later confirmed by Buston et al. (1938). However, Ribeiro et al. (2012) recently verified

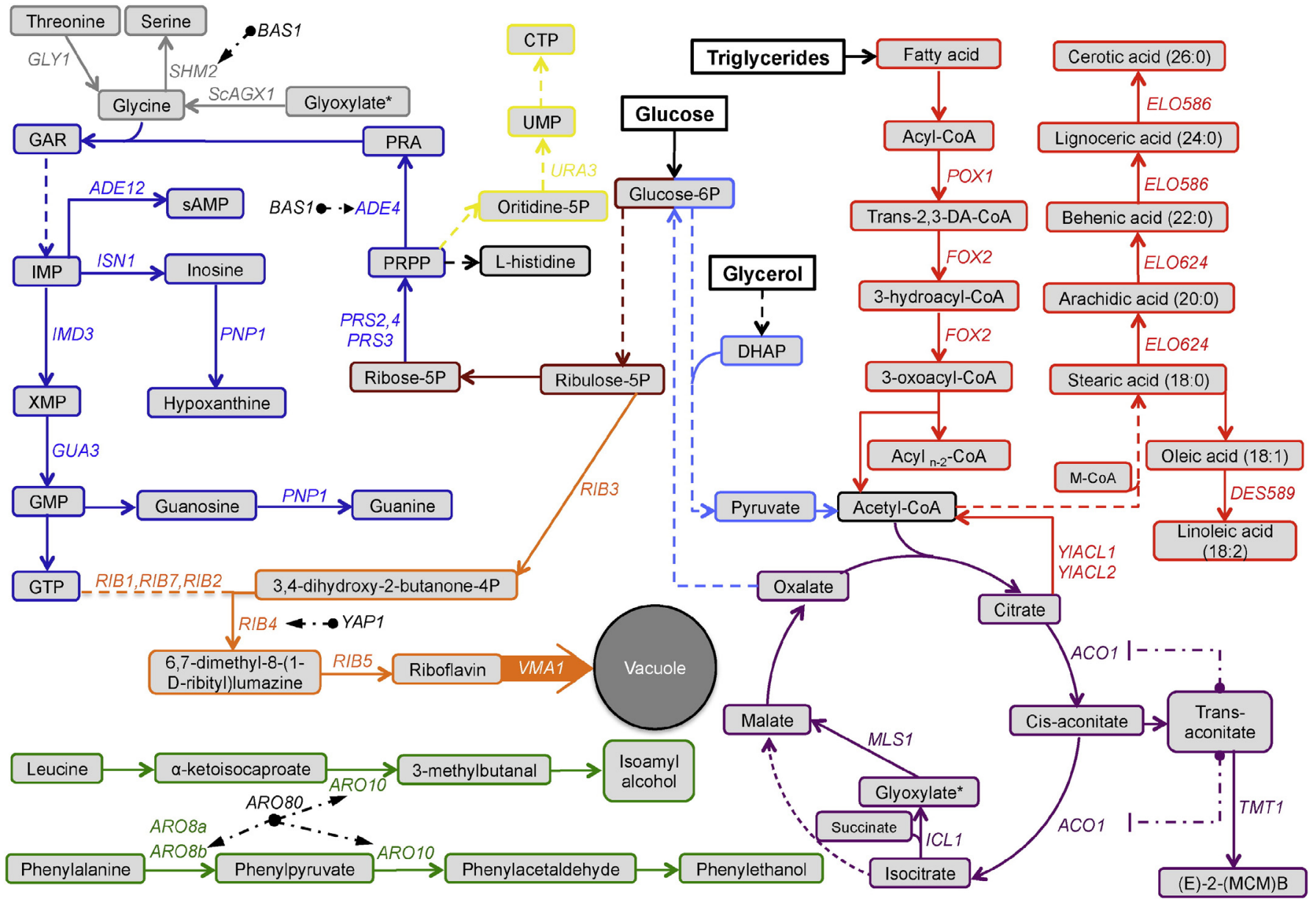

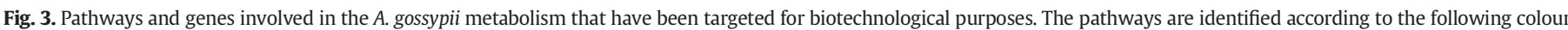

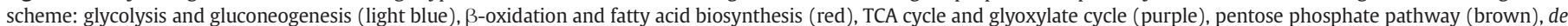

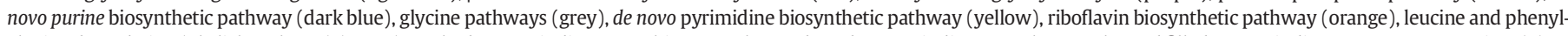

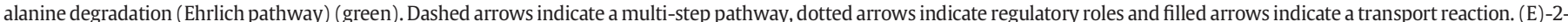

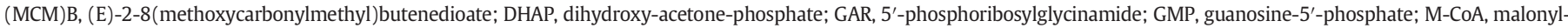

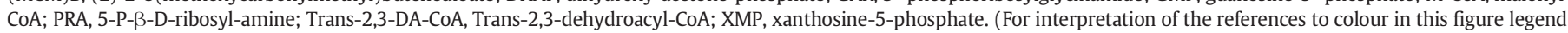
the reader is referred to the web version of this article.) 
that several A. gossypii strains actually grow well on chemically defined medium containing ammonium as sole nitrogen source when the medium $\mathrm{pH}$ is 6.5 , but poorly at $\mathrm{pH} 4.5$, indicating that the lack or limited growth previously reported probably reflected low medium $\mathrm{pH}$. Supporting their observations is the fact that A. gossypii is genetically equipped for ammonium (but not for nitrate) assimilation (Ribeiro et al., 2012).

The sensitivity of A. gossypii to low medium $\mathrm{pH}$ had been previously observed by Tanner et al. (1949), whom verified that media initially adjusted to $\mathrm{pH} 4.0$ gave little growth and riboflavin production. Between $\mathrm{pH} 4.5$ and 5.5 there was a good and rapid multiplication, but the best riboflavin yields were obtained when the initial $\mathrm{pH}$ of the medium was above pH 5.5, preferably in the range of $\mathrm{pH} 6.0$ to 7.0 (Tanner et al., 1949). The growth temperature also has an impact on riboflavin production. Although $A$. gossypii grows over a rather wide temperature range (20 to $40{ }^{\circ} \mathrm{C}$ ), the greatest riboflavin accumulation occurs when cultures are incubated at 26 to $28^{\circ} \mathrm{C}$, which is below the optimum for growth (30 to $35{ }^{\circ} \mathrm{C}$ ) (Özbas and Kutsal, 1986; Pfeifer et al., 1950; Tanner et al., 1949). The presence of low concentrations of $\mathrm{NaCl}$ and $\mathrm{Na}_{3} \mathrm{PO}_{4}$, or slightly higher concentrations of mannitol, sorbitol and $\mathrm{KCl}$, highly inhibit the A. gossypii's growth, displaying this fungus acute sensitivity to hyperosmotic stress (Förster et al., 1998; Nikolaou et al., 2009).

Myo-inositol and biotin have early been found to be required for A. gossypii's growth (Buston and Pramanik, 1931; Farries and Bell, 1930; Kögl and Fries, 1937), as this fungus lacks the genes necessary for their biosynthesis (Gomes et al., 2014). In fact, the A. gossypii's requirement for biotin played an important role in the discovery of this vitamin (Kögl and Fries, 1937). Thiamine is also necessary for adequate growth, as A. gossypii synthesizes it in sub-optimal amounts (Pridham and Raper, 1950). When these "accessory factors" are added to the medium, A. gossypii is capable of utilizing simple mixtures of amino acids, ammonium aspartate or asparagine as nitrogen sources (Buston and Kasinathan, 1933), the latter supporting better growth in defined media (Demain, 1972). Peptone and casein constitute, however, better nitrogen sources for A. gossypii (Farries and Bell, 1930). Yeast extract is also a good source of several nutrients necessary for $A$. gossypii's growth (Wickerham et al., 1946) and we have observed that it alone can support residual growth of $A$. gossypii in liquid medium without addition of carbon source (Aguiar et. al., personal communication). Crude nitrogen and vitamin sources, like animal steep liquor, corn steep liquor and distillers' solubles have, however, been preferably employed in large-scale riboflavin production (Pfeifer et al., 1950; Smiley et al., 1951; Tanner et al., 1949).

Several studies on the $A$. gossypii's carbon requirements indicated that glucose, fructose, sucrose, starch, maltose and glycerol support good growth, but plant oils (such as corn oil and soybean oil) are superior and favour riboflavin production and lipid accumulation (Kutsal and Özbas, 1989; Ledesma-Amaro et al., 2014a; Pridham and Raper, 1950; Ribeiro et al., 2012; Tanner et al., 1949). Ethanol supports more limited growth rates (Pridham and Raper, 1950). Cellulose, pentoses (arabinose, xylose), galactose and lactose are not utilized as carbon sources (Pridham and Raper, 1950; Ribeiro et al., 2012), which may be explained by the absence of enzymes and/or pathways necessary for the metabolism of these substrates in the A. gossypii's genome (Gomes et al., 2014; Ribeiro et al., 2012). Correlated with the limited range of carbon sources that $A$. gossypii utilizes, the variety and amount of hydrolytic enzymes secreted by A. gossypii to the extracellular medium is rather low (Aguiar et al., 2014a; Ribeiro et al., 2010, 2013). Of these, only a lipase and an invertase have been experimentally characterized thus far (Aguiar et al., 2014b; Stahmann et al., 1997).

Under aerobic conditions, glucose is oxidized by A. gossypii more or less completely to carbon dioxide and water (Mickelson, 1950; Mickelson and Schuler, 1953). However, considerable amounts of ethanol and traces of pyruvic, acetic and citric acid are formed during the course of the fermentation (Mickelson, 1950; Mickelson and Schuler,
1953). Volatile fusel alcohols and esters derived from the catabolism of amino acids are also formed via the Ehrlich pathway (Fig. 3), with particularly high level production of isoamyl alcohol and 2-phenylethanol, which confer to A. gossypii's cultures a characteristic fruity/floral aroma (Ravasio et al., 2014). A. gossypii is also able to ferment glucose anaerobically, yielding 2 moles of carbon dioxide per mole of sugar consumed, which approaches the theoretical yield of a typical yeast alcoholic fermentation (Mickelson, 1950). On the other hand, aerobiosis is required for riboflavin overproduction (Demain, 1972; Pfeifer et al., 1950; Tanner et al., 1949).

A. gossypii has been shown to accumulate high amounts of lipid bodies as carbon and energy storage pools (Stahmann et al., 1994; Ledesma-Amaro et al., 2014a). Although the carbon sources utilized play a determinant role in its lipidogenic profile, A. gossypii predominantly accumulates unsaturated fatty acids (FA) (Stahmann et al., 1994; Ledesma-Amaro et al., 2014a). When lipids are used as carbon source, the glyoxylate cycle plays a fundamental role with respect to A. gossypii's growth and riboflavin synthesis, as the precursors of riboflavin, GTP and ribulose 5-P, originate from the carbohydrate metabolism (Fig. 3) (Schmidt et al., 1996a, 1996b). The first enzyme of this pathway, isocitrate lyase (ICL), is essential for catalysing the cleavage of isocitrate to succinate and glyoxylate, thus diverting the carbon flux from the tricarboxylic acid (TCA) cycle into a carbonconserving pathway. The final result of this anaplerotic activity is a net conversion of fats to carbohydrates through gluconeogenesis (Maeting et al., 1999; Schmidt et al., 1996a, 1996b). An extracellular lipase secreted by A. gossypii plays an important role in the degradation of plant oils to fatty acids and glycerol before their uptake into intracellular organelles (where $\beta$-oxidation takes place) (Maeting et al., 2000; Stahmann et al., 1997). Addition of non-ionic surface active agents to the culture medium (like Tween 80) stabilizes the activity of this enzyme (Stahmann et al., 1997) and enhances riboflavin production (Demain, 1972; Goodman and Ferrera, 1954).

Riboflavin biosynthesis is closely related to other biosynthetic pathways, such as the purine synthesis pathway (Fig. 3), all of which compete for the same substrates. In addition to being directly used in the riboflavin biosynthesis pathway, ribulose 5-P can alternatively be isomerized to ribose 5-P (Kruger and von Schaewen, 2003). GTP, the other riboflavin precursor, is synthesized through the purine pathway, which starts with the formation of phosphoribosyl pyrophosphate (PRPP) from ribose 5-P and ATP. Interestingly, A. gossypii was recently shown to secrete high amounts of inosine and guanosine, which are purine nucleosides produced via this same pathway (Ledesma-Amaro et al., 2015). PRPP is not only required for the de novo and salvage pathways of purine, pyrimidine and pyridine $\left(\mathrm{NAD}^{+}, \mathrm{NADP}^{+}\right)$nucleotides, but also as a precursor of histidine (Fig. 3) and tryptophan biosynthesis (Jiménez et al., 2008). The addition of purines (like hypoxanthine) and, most importantly, glycine to the culture medium has yield-enhancing effects on riboflavin production (Demain, 1972; Monschau et al., 1998). Glycine is an important precursor during the de novo purine biosynthesis and is endogenously obtained through the conversion of threonine by the AgGly1p threonine aldolase (Monschau et al., 1998).

One important aspect of the A. gossypii physiology that needs to be emphasized is the fact that significantly different sporulation efficiencies and growth parameters, such as colonial radial growth rate, have been reported not only for different strains within the species but also for the same strain deposited in different culture collections (Ribeiro et al., 2012). This inherent plasticity of A. gossypii also affects riboflavin production/accumulation, as Nieland and Stahmann (2013) recently showed that A. gossypii hyphal cells growing in the same culture exhibit phenotypic differences in what concerns overproduction and accumulation of riboflavin. Therefore, one must be cautious when analysing the available data on the metabolism and physiology of this fungus.

Recent findings reporting the existence of differences between the mating type of different A. gossypii strains (Dietrich et al., 2013) and of variable degrees of ploidy within the same cell at different cell cycle 
stages (Anderson et al., 2015) may help explain why physiological and metabolic differences are observed between and within strains, and thus warrant further investigation. On the other hand, as the production of industrially interesting metabolites varies significantly among wild strains (Ledesma-Amaro et al., 2015), the systematic exploration of this fungus natural biodiversity may unravel new biotechnological potential for A. gossypii, and should therefore be considered as a standard procedure in the development of novel applications (see Section 4).

\section{Molecular toolbox}

Various genetic tools and molecular methods have been developed for use in A. gossypii, among which random mutagenesis with physical (ultraviolet (UV) radiation) or chemical (nitrogen mustard, N-methyl$\mathrm{N}^{\prime}$-nitro-N-nitrosoguanidine (MNNG) and ethyl methane sulfonate (EMS)) mutagens followed by screening of colonies with the desired phenotype has been the methodology used for the longest time to generate and isolate A. gossypii mutants with improved traits (Park et al., 2007; Pridham and Raper, 1952; Perlman, 1979; Ribeiro et al., 2013; Schmidt et al., 1996a; Tajima et al., 2009). In fact, random mutagenesis has been the main classical genetic approach used to manipulate A. gossypii strains, although adaptive evolution strategies under selective conditions also allowed isolating spontaneous mutants with improved phenotypes (Pfeifer et al., 1950; Sugimoto et al., 2010). Other random mutagenesis techniques that do not involve the use of chemical or physical mutagens have also been used to generate genetic diversity in A. gossypii, such as insertional mutagenesis by in vitro transposition (Santos et al., 2005) and disparity mutagenesis using an error-prone DNA polymerase (Park et al., 2011). The absence of a known sexual cycle in this fungus has impeded the use of other classical genetic approaches (Dietrich et al., 2013; Wendland et al., 2011). A significant technical difficulty associated with the A. gossypii mutagenic screens that needs to be highlighted is the inability to easily isolate single spores, as they clump together via terminal filaments (Wendland et al., 2011).

With the introduction of recombinant DNA technology in A. gossypii, reverse genetic approaches have been added to mutational techniques as a means to further improve strains in a rational way. Transformation methods for inserting foreign DNA into A. gossypii were initially developed by Wright and Philippsen (1991). The surprising result of their study was that freely replicating plasmids are propagated in A. gossypii based on S. cerevisiae autonomously replicating sequences (ARS) (ARS1 and 2-micron). However, an ARS element and centromere of the A. gossypii chromosome $\mathrm{V}$, which function in Holleya sinecauda (a close relative of A. gossypii; Kurtzman, 1995), were found not to be functional in S. cerevisiae (Schade et al., 2003). S. cerevisiae centromeres do not function in A. gossypii as well (Wendland and Walther, 2005). Plasmids containing S. cerevisiae ARS elements have been widely used since to express homologous and heterologous genes in A. gossypii (Aguiar et al., 2014b; Altmann-Jöhl and Philippsen, 1996; Ayad-Durieux et al., 2000; Kato and Park, 2006; Magalhães et al., 2014; Monschau et al., 1998; Ribeiro et al., 2010).

Strong, constitutive promoters are available for driving homologous and heterologous gene expression in A. gossypii, such as those of the A. gossypii translation elongation factor $1 \alpha$ (AgTEF) or glyceraldehyde3-phosphate dehydrogenase (AgGPD) (Revuelta et al., 1999; Steiner and Philippsen, 1994). The S. cerevisiae's TEF2, PDC1, PGK1, LEU2 and $A D H 1$ constitutive promoters have also been used to drive the expression of genes in A. gossypii (Kaufmann, 2009; Magalhães et al., 2014; Ribeiro et al., 2010; Wendland et al., 2000). Regulatable promoters, such as the A. gossypii's and S. cerevisiae's MET3, the S. cerevisiae's THI13 and the A. gossypii's SUC2 promoters have been described to regulate the expression of genes in A. gossypii as well (Aguiar et al., 2014b; Dünkler and Wendland, 2007; Kaufmann, 2009).

Another interesting characteristic of A. gossypii is that, in contrast to other filamentous fungi and similarly to $S$. cerevisiae, it has a highly efficient homologous recombination system (Steiner et al., 1995). This has facilitated the establishment of simple PCR-based gene targeting techniques in A. gossypii (Wendland et al., 2000). Integrative transformation of $A$. gossypii results in primary heterokaryotic transformants, which contain both wild and mutant nuclei. These heterokaryotic transformants generate uninucleate spores that when grown under selective conditions allow the isolation of homokaryotic mutants (Steiner et al., 1995). Thus, compared with other filamentous fungi, gene analysis in A. gossypii is particularly straightforward.

A. gossypii strains auxotrophic for threonine (Agthr4 $\Delta$; Altmann-jöhl and Philippsen, 1996) and leucine (Agleu2 $\Delta$; Ayad-Durieux et al., 2000) have been developed for use in molecular genetic studies. These auxotrophies are complemented by the corresponding $S$. cerevisiae homologue genes (Altmann-Jöhl and Philippsen, 1996; Ayad-Durieux et al., 2000). Several heterologous selectable marker cassettes for dominant selection have also been developed, such as the GEN3, NATPS and BLE3 marker cassettes, which confer resistance to G418/geneticin (Wendland et al., 2000), clonNAT/nourseothricin (Hoepfner in Kaufmann, 2009) and phleomycin (Ribeiro et al., 2013), respectively. A hygromycin resistance $\left(\mathrm{Hyg}^{r}\right)$ marker gene has also been used to select A. gossypii transformants (Jiménez et al., 2008; Mateos et al., 2006).

Reporter proteins, like the Escherichia coli and Aspergillus niger $\beta$ galactosidase and the green fluorescent protein (GFP), have been widely used in A. gossypii to study gene expression and protein localization (Ayad-Durieux et al., 2000; Dünkler and Wendland, 2007; Gladfelter et al., 2006; Magalhães et al., 2014; Monschau et al., 1998; Walther and Wendland, 2012). In this context, Kaufmann (2009) developed a plasmid collection for PCR-based gene targeting in A. gossypii that covers a wide selection of modules for fluorescent protein tagging combined with different heterologous selection markers. Additionally, several fluorescent dyes can be used in A. gossypii to stain various cellular organelles and cytoskeleton structures (Gladfelter et al., 2006; Walther and Wendland, 2004; Wendland and Philippsen, 2001).

Important molecular tools for genetic manipulation of A. gossypii have been established, but optimal strain design for industrial applications requires flexible transformation systems that allow the removal and recycling of exogenous marker genes, especially those conferring resistance to antibiotics. With this in mind, the Cre-loxP recombination system of the bacteriophage P1 was adapted for generating A. gossypii strains free of exogenous marker genes, opening new perspectives for the deletion and/or integration of multiple genes (Aguiar et al., 2014c). In the scope of this work, three heterologous recyclable drug marker cassettes and two Cre recombinase expression vectors were created, being suitable for use in both laboratorial and industrial A. gossypii strains, as they do not require any predetermined genetic background. These tools also allowed the generation of stable auxotrophic strains for uridine/uracil (Agura3 $\Delta)$, adenine (Agade1 $\Delta)$ and both (Agura3 $\Delta$, Agade1 $\Delta$ ) (Aguiar et al., 2014c). Unlike the others auxotrophies already mentioned (A. gossypii Agleu2 $\Delta$ and Agthr $4 \Delta$ strains), the corresponding S. cerevisiae's homologue could not complement the deletion of AgURA3 (Pompejus et al., 1999). Therefore, these auxotrophic strains will be important for future engineering projects as soon as a selection system based on the complementation of these auxotrophies becomes available.

All these molecular tools have been important for the development of stable A. gossypii strains for biotechnological purposes (as it will be discussed in the following section), but the improvement of existing tools and development of new ones will be crucial to meet the demands of the biotechnology industry and to develop A. gossypii as a new cell factory. In this regard, the establishment of flexible genome editing methods (e.g., CRISPR-Cas system; DiCarlo et al., 2013) for engineering this fungus is of great interest. Moreover, as the number of characterized promoters currently available for use in A. gossypii is limited, screening and identification of other promoters with desired characteristics will settle the basis for the development of new and more flexible gene 
expression tools. Similar screening strategies should be followed for designing new reporter proteins and secretion signal sequences for use in the scope of recombinant protein production. Beyond these pressing needs, a major outcome of the upcoming years may be related with the arising of forward genetic tools for A. gossypii, fading away the dependency on reverse genetics. However, significant work is still needed in order to elucidate the conditions needed for sexual reproduction. The first step has already been taken with the isolation of wild A. gossypii strains possessing mating type regions distinct from those presented by the first sequenced strain, ATCC10895 (Dietrich et al., 2013).

\section{Commercial and emerging biotechnological applications}

The filamentous fungus $A$. gossypii presents several industrially attractive features, such as good performance in large-scale fermentation processes and ability to grow in inexpensive waste-derived substrates to high cell densities (Park et al., 2007; Tajima et al., 2009; Wei et al., 2013). Its capacity to secrete proteins and metabolites to the culture medium and to undergo autolysis during the late stationary phase of growth or at low temperature is also industrially appealing, as they facilitate downstream product recovery (Aguiar et al., 2014a; zu Berstenhorst et al., 2009). These features, combined with the successful industrial process of riboflavin production by A. gossypii and with the availability of several tools for its easy genetic manipulation, have raised attention to this fungus for the production of other metabolites and/or proteins. In the last year, systems biology provided essential in silico predictive tools to optimize existing and develop new biotechnological applications for A. gossypii. In this context, the A. gossypii genome was re-annotated (Gomes et al., 2014) and its reaction set compiled to create a genome scale metabolic model (GSMM) able to simulate the cell behaviour, being now this model in its experimental validation phase (Gomes et al., personal communication). Other GSMM for A. gossypii was already published (iRL766) and successfully validated by predictions and comparisons for three experimental parameters: biomass growth, riboflavin production and substrate utilization (LedesmaAmaro et al., 2014b). Together, these new tools are leveraging the A. gossypii potential as a cell factory organism.

\subsection{Riboflavin production}

A. gossypii constitutes a paradigm of the sustainable White Biotechnology with regard to industrial riboflavin production. Riboflavin is a precursor of the flavin mononucleotide (FMN) and flavin adenine dinucleotide (FAD), which are essential co-factors for numerous enzymes (including dehydrogenases, oxidases, oxidoreductases) that participate in a range of redox reactions critical for major biological processes. This vitamin is commercially used as a yellow colourant and animal food additive, and for many years it was mainly obtained by chemical synthesis, until its industrial production shifted to microbial fermentation (Stahmann et al., 2000; zu Berstenhorst et al., 2009). As an outcome of classical improvement of naturally overproducing strains by random mutagenesis and optimization of culture conditions, the industrial fermentation process using A. gossypii for riboflavin production is among the first biotechnological processes that replaced the chemical process in use due to its higher economical competitiveness (Kato and Park, 2012; Lim et al., 2001; Stahmann et al., 2000; zu Berstenhorst et al., 2009).

Wild A. gossypii strains have been reported to produce up to $5 \mathrm{~g} / \mathrm{L}$ of riboflavin in optimized culture media, but randomly improved strains can produce from 14 to $20 \mathrm{~g} / \mathrm{L}$ of riboflavin (Demain, 1972; Lim et al., 2001; Park et al., 2011). Many randomly improved A. gossypii strains for riboflavin production were obtained by several rounds of mutagenesis followed by screening of colonies with increased yellow pigmentation (Perlman, 1979). Since the industrial establishment of this process, different mutagenic agents and screening procedures were adopted and combined in different manners (Table 1). UV radiation (Park et al., 2007; Schmidt et al., 1996b; Wei et al., 2012), chemical mutagens (Lizama et al., 2007; Tajima et al., 2009) and disparity mutagenesis (Park et al., 2011) have been applied to create mutations. For the screening procedures, antimetabolites (mainly itaconate and oxalate) have been the most common way to isolate overproducing strains, essentially due to the correlation between the A. gossypii isocitrate lyase (Icl1p; glyoxylate cycle) activity and riboflavin production (Schmidt et al., 1996a, 1996b). In fact, Sugimoto et al. (2010) were able to isolate a riboflavin overproducing strain only by growing A. gossypii spores in a medium containing oxalate, without the application of any mutagenic agent. More recently, through the analysis of the itaconate metabolism and genetics, its related compounds cis-aconitate and trans-aconitate were detected in the riboflavin production phase and, as the latter has an inhibitory effect on aconitase in the TCA, the authors proposed trans-aconitate as a novel and more available antimetabolite for screening of riboflavin overproduction (Sugimoto et al., 2014).

Since the 1990s, when BASF (Germany) launched a riboflavin production plant with A. gossypii, the performance of A. gossypii strains could be much improved by rational design as well. The constantly increasing molecular toolbox for this fungus (see Section 3 ) and the deep understanding acquired along the last two decades about the A. gossypii riboflavin biosynthetic pathway (reviewed in Kato and Park, 2012) supported this. Among the rational strategies tested (Table 2), the majority focused on increasing the flux of the riboflavin biosynthetic pathway and of the purine/glycine biosynthetic pathways by (1) overexpressing the AgRIBs genes (Althöefer et al., 1999; Althöefer and Revuelta, 2003); (2) overexpressing the AgGLY1 gene, involved in the conversion of threonine to glycine (Monschau et al., 1998); (3) disrupting the AgSHM2 gene, which encodes a cytosolic serine hydroxymethyltransferase that converts glycine into serine (Schlüpen et al., 2003); (4) overexpressing the $S$. cerevisiae's AGX1 gene, which is not present in A. gossypii and encodes an alanine:glyoxylate aminotransferase that converts glyoxylate into glycine (Kato and Park, 2006); (5) overexpressing

Table 1

Random engineering approaches applied in A. gossypii for biotechnological purposes.

\begin{tabular}{|c|c|c|c|}
\hline Mutagen & Screening & Application & Reference(s) \\
\hline UV light & Antimetabolite (itaconate) & Riboflavin & Park et al. (2007), Schmidt et al. (1996b) \\
\hline UV light & Yellow colour of the colonies & Riboflavin & Wei et al. (2012) \\
\hline MNNG & Antimetabolite (itaconate) & Riboflavin & Lizama et al. (2007), Tajima et al. (2009) \\
\hline- & Antimetabolite (oxalate) & Riboflavin & Sugimoto et al. (2010) \\
\hline Mutated DNA polymerase $\delta$ & $\begin{array}{l}\text { Antimetabolite (oxalate and hydrogen peroxide) } \\
\text { Regeneration of the colonies by serial transfers in selective medium } \\
\text { Stabilization of the colonies in non-selective medium and quantification } \\
\text { of riboflavin production }\end{array}$ & Riboflavin & Park et al. (2011) \\
\hline EMS & $\begin{array}{l}\text { Selective medium containing } \mathrm{CMC}^{\mathrm{a}} \text { (for EGI), starch (for } \alpha \text {-amylase) or } \\
\text { tributyrin (for lipase) } \\
\text { Determination of specific enzymatic activities }\end{array}$ & $\begin{array}{l}\text { Recombinant protein } \\
\text { production }\end{array}$ & Ribeiro et al. (2013) \\
\hline
\end{tabular}

\footnotetext{
a Carboxymethylcellulose.
} 
Table 2

Target genes of rational genetic engineering strategies in A. gossypii for different biotechnological applications.

\begin{tabular}{|c|c|c|}
\hline Gene & Strategy and outcome & Reference(s) \\
\hline & Riboflavin production & \\
\hline AgRIB3-5 & $\begin{array}{l}\text { Overexpression increased the flux of the riboflavin biosynthetic pathway, which resulted in } \\
\text { a } 2.5 \text {-fold increase in riboflavin production }\end{array}$ & Althöefer et al. (1999) \\
\hline $\operatorname{AgGLY1}$ & $\begin{array}{l}\text { Overexpression increased glycine formation from threonine, which allowed a 9-fold increase } \\
\text { in specific riboflavin production }\end{array}$ & Monschau et al. (1998) \\
\hline AgSHM2 & $\begin{array}{l}\text { Disruption abolished the conversion of glycine into serine, which led to a 10.6-fold increase in } \\
\text { specific riboflavin production }\end{array}$ & Schlüpen et al. (2003) \\
\hline AgADE4 & $\begin{array}{l}\text { Overexpression and elimination of feedback inhibition by site directed mutagenesis increased the } \\
\text { flux of the purine biosynthetic pathway, which resulted in a } 10 \text {-fold increase in riboflavin production }\end{array}$ & Jiménez et al. (2005) \\
\hline$A g P R S 2,4$ and $A g P R S 3$ & $\begin{array}{l}\text { Overexpression and elimination of feedback inhibition by site directed mutagenesis increased PRPP } \\
\text { availability, which resulted in an } 1.7 \text { - to } 1.8 \text {-fold increase in riboflavin production }\end{array}$ & Jiménez et al. (2008) \\
\hline$A g B A S 1$ & $\begin{array}{l}\text { Deletion of the C-terminal interaction and regulatory domain constitutively activated the purine and } \\
\text { glycine pathways, which resulted in a } 9.4 \text {-fold increase in specific riboflavin production }\end{array}$ & Mateos et al. (2006) \\
\hline AgVMA1 & Recombinant protein production & \\
\hline ShcelA1 & Heterologous expression allowed the recombinant production of $S$. halstedii endo- $\beta-1,4$-glucanase & Althöefer et al. (2001) \\
\hline TreglI and $\operatorname{TrcbhI}$ & Heterologous expression allowed the extracellular production of T. reesei $\mathrm{EGI}$ and CBHI & Ribeiro et al. (2010) \\
\hline AnlacA & Heterologous expression allowed the extracellular production of $A$. niger $\beta$-galactosidase & Magalhães et al. (2014) \\
\hline \multirow[t]{2}{*}{ SCSUC2 } & Heterologous expression allowed the extracellular production of S. cerevisiae invertase & Aguiar et al. (2014b) \\
\hline & Single cell oil production & \\
\hline YIACL1/YIACL2 & $\begin{array}{l}\text { Heterologous expression enabled the production of acetyl-CoA from citrate, which increased lipid } \\
\text { accumulation during the trophic phase (by } 1.3 \text {-fold) }\end{array}$ & Ledesma-Amaro et al. (2014a) \\
\hline$A g P O X 1$ and $A g F O X 2$ & $\begin{array}{l}\text { Disruption blocked the beta-oxidation pathway, which triggered a 2- to } 3.5 \text {-fold increase in lipid } \\
\text { accumulation }\end{array}$ & Ledesma-Amaro et al. (2014a) \\
\hline AgELO586 & $\begin{array}{l}\text { Overexpression increased cerotic acid ( } 26: 0 \text { ) accumulation and disruption resulted in SCO with } \\
\text { properties that meet some biodiesel quality standards }\end{array}$ & Ledesma-Amaro et al. (2014c) \\
\hline AgISN1 & Disruption did not increase inosine excretion & Ledesma-Amaro et al. (2015) \\
\hline AgGUA1 & Overexpression increased riboflavin production but did not increase guanosine excretion & Ledesma-Amaro et al. (2015) \\
\hline AgRIB1 & Down regulation reduced riboflavin production but did not increase guanosine excretion & Ledesma-Amaro et al. (2015) \\
\hline
\end{tabular}

Ag, A. gossypii; An, A. niger; Sc, S. cerevisiae; Sh, S. halstedii; Tr, T. reesei; Yl, Y. lipolytica.

several genes involved in the purine biosynthetic pathway such as AgADE4 (Jiménez et al., 2005), AgPRS2,4 and AgPRS3 (Jiménez et al., 2008); (6) deregulating the transcription factor AgBas1p that constitutively activates the purine and glycine biosynthetic pathways (Mateos et al., 2006); and (7) blocking the A. gossypii's de novo pyrimidine biosynthetic pathway by deletion of the AgURA3 gene (Aguiar et al., 2014c) to increase the availability/accumulation of PRPP for the formation and/or accumulation of riboflavin precursors (GTP and ribulose-5P; Silva et al., 2015). Other strategies focused on improving riboflavin production from plant oils by overexpressing genes involved in the glyoxylate cycle, such as the AgICL1 (Käsler et al., 1997) and the AgMLS1 (encoding the malate synthase; Sugimoto et al., 2009), and on increasing the excretion of riboflavin into the medium by disrupting the gene encoding the vacuolar ATPase subunit A, AgVMA1 (Förster et al., 1999).

An increasing number of evidences have shown that the triggering of riboflavin overproduction in A. gossypii is associated with the activation of intracellular stress signalling cascades in response to environmental changes (Kavitha and Chandra, 2009, 2014; Walther and Wendland, 2012; Nieland and Stahmann, 2013). Therefore, future attempts to further improve riboflavin production will rely on the better understanding of the overall stress responses of A. gossypii. Meanwhile, the knowledge already gained with $A$. gossypii will serve as a basis to guide the improvement of riboflavin production by other cell factories.

\subsection{Recombinant protein production}

Beyond riboflavin production, the exploration of $A$. gossypii as a host for the production of heterologous proteins has received much attention in the last years. An endo- $\beta$-1,4-glucanase (celA1) from Streptomyces halstedii (Althöefer et al., 2001), two cellulases from Trichoderma reesei, endoglucanase I (EGI) and cellobiohydrolase I (CBHI) (Ribeiro et al., 2010), a $\beta$-galactosidase from Aspergillus niger (Magalhães et al., 2014) and a S. cerevisiae's invertase (Aguiar et al., 2014b) are among the repertoire of heterologous enzymes already produced in this host system (Table 2).

A. gossypii possesses the ability to secrete native and heterologous enzymes to the extracellular medium and to recognize signal peptides of other organisms as secretion signals (Aguiar et al., 2014b; Althöefer et al., 2001; Magalhães et al., 2014; Ribeiro et al., 2010; Stahmann 
et al., 1997). The amount and variety of native proteins secreted by this fungus are low, being its secretory potential more similar to that of yeast than to that of other filamentous fungi (Aguiar et al., 2014a). In line with this observation, the protease activity in A. gossypii culture supernatants is negligible (Ribeiro et al., 2010). Together, these features represent important advantages for heterologous protein production in this host, as secreted products are less likely to be contaminated or degraded by native proteins, thus allowing cost-efficient downstream processing of low- and medium-value enzymes.

A. gossypii is also able to perform protein post-translation modifications, such as glycosylation and other modifications required for the biological activity and stability of proteins (Aguiar et al., 2013; Magalhães et al., 2014; Ribeiro et al., 2010). Compared to the closely related yeast S. cerevisiae, one of the fungal hosts most commonly used for the production of heterologous proteins (Demain and Vaishnav, 2009), A. gossypii has the tendency to hyperglycosylate secreted glycoproteins less extensively, as disclosed by the glycosylation pattern of the heterologous EGI, CBHI (Ribeiro et al., 2010) and $\beta$-galactosidase (Magalhães et al., 2014). This is advantageous for the production of proteins whose properties may be adversely affected by extensive glycosylation. A recent characterization of its secreted $\mathrm{N}$-glycome corroborates these data, as A. gossypii revealed a processing system substantially distinct from that of $S$. cerevisiae, which allows the production of much shorter $\mathrm{N}$-glycans (Aguiar et al., 2013). In fact, this study showed that A. gossypii predominantly produces $\mathrm{N}$-glycans that are more similar in extent to those produced by nonconventional yeast hosts such as Pichia pastoris, Hansenula polymorpha and Yarrowia lipolytica (Aguiar et al., 2013). Nevertheless, the extent of $\mathrm{N}$-glycosylation and $\mathrm{N}$-glycan phosphorylation in A. gossypii is highly influenced by the culture medium used (Aguiar et al., 2013).

Despite these advantages, the production levels reported for the first heterologous proteins secreted by A. gossypii (EGI and CBHI) were low, although comparable to those obtained with S. cerevisiae (Ribeiro et al., 2010). In fact, the obtainment of reasonable amounts of these cellulases by recombinant microbial hosts in a biologically active form has been a challenging task (Ribeiro et al., 2010). Therefore, further investigation of A. gossypii as a recombinant protein production host went through the implementation of random engineering techniques to improve its general secretory capacity. In this context, the recombinant $A$. gossypii strain expressing EGI was exposed to the chemical mutagen EMS (Ribeiro et al., 2013). The following screening strategy was initially based on the diameter of the haloes formed around the mutant colonies on screening media for different enzymatic activities (Table 1). Among the activities tested, only cellulolytic activity gave a good correlation and allowed the selection of the most promising mutants (Ribeiro et al., 2013). Subsequently, these mutants were grown in submerged cultures and extracellular activities were determined for heterologous cellulase ( $T$. reesei $\mathrm{EGI}$ ), native $\alpha$-amylase and native $\beta$-glucosidase. One mutant exhibiting a superior performance (of 1.4- to 2-fold) in all extracellular enzymatic activities was identified, suggesting a global improvement in its secretory capacity (Ribeiro et al., 2013). Other mutants also presented partial improvements (of 2- to 3-fold): two in EGI or $\beta$ glucosidase activity, and one in EGI and $\alpha$-amylase activities (Ribeiro et al., 2013). Another attempted to increase the general secretory potential of this fungus involved the deletion of AgGAS1 homologues (encoding a $\beta$-1,3-glucanosyltransglycosylase involved in cell wall assembly) to enhance the permeability of the cell wall, but the resulting mutants presented serious growth defects (Ribeiro et al., 2013).

Transcriptomic analysis performed in A. gossypii cells under recombinant protein secretion conditions and dithiothreitol-induced secretion stress subsequently provided useful information about possible strategies that could be used to further improve its productivity (Aguiar et al., 2014a). Among these, the use of stronger promoters was found to be of upmost importance, as the heterologous S. cerevisiae PGK1 constitutive promoter was proved to be inefficient in driving the overexpression of the EGI-encoding gene (Aguiar et al., 2014a). This study also revealed the existence in A. gossypii of alternative regulatory mechanisms to cope with protein secretion stress, other than the conventional unfolded protein response (UPR), which may offer novel ways of improving protein secretion in this fungus (Aguiar et al., 2014a).

The strength of several native (A. gossypii TEF and GPD) and heterologous (S. cerevisiae PGK1 and ADH1) constitutive promoters was compared when producing a heterologous protein of other origin, the $\beta$ galactosidase from A. niger (Magalhães et al., 2014). Given the ease of detection of this secreted enzyme, the screening of transformants was facilitated. Moreover, as this protein had already been efficiently secreted by recombinant S. cerevisiae strains (Domingues et al., 2002, 2005; Oliveira et al., 2007; Ramakrishnan and Hartley, 1993), it provided a good model protein to further explore the potential of A. gossypii as a heterologous protein producer. The strong $A$. gossypii's TEF promoter drove the highest production levels of this enzyme in A. gossypii and $S$. cerevisiae laboratorial strains, followed by the other native promoter tested, GPD (Magalhães et al., 2014). Using the TEF promoter, A. gossypii secreted up to 37 -fold more active $\beta$-galactosidase than two different S. cerevisiae strains transformed with the same plasmids (Magalhães et al., 2014). In similar culture conditions, A. gossypii also produced 2.5fold more extracellular $\beta$-galactosidase than that previously reported for a $\beta$-galactosidase high-producing $S$. cerevisiae strain transformed with a different plasmid under the control of the S. cerevisiae's $A D H 1$ promoter (Domingues et al., 2002; Magalhães et al., 2014). However, much can still be improved just by manipulating the production conditions, as demonstrated by the 1.5-fold increase in $\beta$-galactosidase secretion when glucose was replaced by glycerol in the culture medium, which allowed reaching extracellular activity levels $(1127 \mathrm{U} / \mathrm{mL})$ within the range of those reported for nonmodified A. niger strains (152 to $3000 \mathrm{U} / \mathrm{mL}$ ) (Magalhães et al., 2014).

In summary, the potential of $A$. gossypii as a host for heterologous protein production is still underexplored and much could be learned about possible strategies to improve its productivity, among which are as follows: (1) culture medium optimization; (2) screening for better promoters and secretion signal sequences; and (3) development of better expression strategies, preferably through the integration of stable expression cassettes.

\subsection{Single cell oil}

The adaptation of A. gossypii for SCO production is a perfect example of how the molecular (see Section 3) and in silico toolbox made available in recent years for this fungus allowed to rationally capitalize its natural abilities (see Section 2.4). SCO is an alternative source to the oil industry, which has seen its main sources (crude oil, animal fat and plant oil) linked to negative environmental and economical effects (Beopoulos et al., 2011). In spite of being considered a non-oleaginous microorganism (Vorapreeda et al., 2012), A. gossypii was metabolically engineered to fit the requisites of a candidate for SCO production (minimum of $20 \%$ lipid content in relation to its cell dry weight) (Ledesma-Amaro et al., 2014a). Two different strategies were used (Ledesma-Amaro et al., 2014a): first, the genes AgPOX1 and AgFOX2, which are involved in the $\beta$-oxidation pathway, were disrupted to avoid FA degradation; second, a heteromeric ATP-citrate lyase (Aclp) from Y. lipolytica was overexpressed in A. gossypii to enable the conversion of citrate into acetyl-CoA and thus increase the pool of this crucial FAs building block.

Single mutants (pox $1 \Delta$ or fox $2 \Delta$ ) with the $\beta$-oxidation pathway blocked were able to improve the accumulation of FAs in media containing only glucose or glucose and oils (Ledesma-Amaro et al., 2014a). In turn, the double mutant strain (pox1 $\Delta$ fox $2 \Delta$ ) did not present any advantage in relation to the single mutants. When oils were supplied as the sole carbon source, all of these strains presented growth limitation (Ledesma-Amaro et al., 2014a). The pox1 $\Delta$ mutant revealed to be the most efficient strain, reaching a lipid content of approximately $40 \%$ (after 3 days of growth) and 70\% (after 7 days of growth) of its dry 
weight (Ledesma-Amaro et al., 2014a). The heterologous overexpression of YlACL1/YlACL2 (encoding both subunits of Aclp from Y. lipolytica) also fulfilled the goal for which it was originally proposed, i.e., increase the cellular pool of acetyl-CoA (Ledesma-Amaro et al., 2014a). Thus, the A. gossypii YlACL1/YlACL2 strain presented superior lipid accumulation, fulfilling the requirements of oleaginous microorganisms in terms of lipid accumulation. However, the A. gossypii pox1 $\triangle, Y l A C L 1 / Y I A C L 2$ strain did not translate the higher levels of acetyl-CoA available into more lipid accumulation in comparison with the A. gossypii pox1 $\Delta$ (LedesmaAmaro et al., 2014a). The pox1 $\Delta$ strain revealed a metabolic unbalance that increased the acetyl-CoA pool independently of the Aclp presence and some other cellular mechanisms benefited from these higher levels of acetyl-CoA (Ledesma-Amaro et al., 2014a). Hence, as suggested by the authors, this increase in acetyl-CoA pools can be valuable in the future to explore the production of other relevant products beyond SCO, such as biobutanol.

The potential applications of SCO are strictly connected with the FA profile of the strain, which should be manipulated according to the requisites of a particular industry. This FA profile is largely defined by the action of enzymes such as the elongases and desaturases, which are responsible for the length and unsaturations of FAs, respectively (Hashimoto et al., 2008). In this regard, Ledesma-Amaro et al. (2014c) performed a functional characterization of selected genes of the elongation (AgELO586 and AgELO624) and desaturation (AgDES589 and $A g D E S 079$ ) system of $A$. gossypii, which had already been identified by Hashimoto et al. (2008). After testing the functionality of the respective proteins in S. cerevisiae, only AgDES079 did not match its predicted function, not showing any notable role in FA desaturation (Ledesma-Amaro et al., 2014c). The regulation of these genes by the carbon source used (glucose or soybean oil) was also checked by analysis of their transcription levels. Once again, AgDES079 was the only gene that did not present any changes (Ledesma-Amaro et al., 2014c). Finally, all genes were independently overexpressed or deleted in A. gossypii. Excluding AgDES079, the manipulation of the other three genes generated a repertoire of strains that can be applied in different industries according to their FA profile (Table 2). For instance, the engineered strains A. gossypii elo586 $\Delta$ and A. gossypii elo624 $\Delta$ fulfilled the restrictive requirements established by the European biodiesel quality standard EN 14214, and are therefore very promising for application in this industry (Ledesma-Amaro et al., 2014c).

The adaptation of A. gossypii for SCO presented very consistent and promising results. According to Ledesma-Amaro et al. (2014a), the $70 \%$ of lipid accumulation achieved in the engineered A. gossypii strains are among the highest accumulation levels reported so far in both oleaginous and nonoleaginous microorganisms. Moreover, the strains created by metabolic engineering of the elongation and desaturation systems have a wide application spectrum in other industrial sectors, such as cosmetics, food, paper and pharmaceutical industry (LedesmaAmaro et al., 2014c).

\subsection{Flavour compounds' production}

The fermented beverages sector invests strongly in new products that can offer a new variety of flavour/aroma perceptions, which are determinant features for product quality. Therefore, there is a continuous effort for screening the biodiversity in order to find new natural producers. In this regard, there is a growing interest on non-Saccharomyces species as natural flavour producers, which many believe to remain largely underexplored (Domizio et al., 2010).

The Ehrlich pathway plays an important role in the metabolism of flavour/aromatic compounds and Wendland and Walther (2011) noticed significant genetic differences between $A$. gossypii and its closely related E. cymbalariae regarding this pathway. E. cymbalariae harbours only one gene related with this pathway (ARO8a), whereas A. gossypii encodes four genes (AgARO8a, AgARO8b, AgARO10 and AgARO80). In comparison with S. cerevisiae, A. gossypii lacks ARO9 (Ravasio et al., 2014). Therefore, Ravasio et al. (2014) decided to characterize and explore the importance of this pathway in flavour production by A. gossypii. The profile of volatile compounds produced by A. gossypii is characterized by high levels of 2-phenylethanol (rose/flower aroma), which are residual in E. cymbalariae, and of isoamyl alcohol (banana/ fruity aroma), also elevated in E. cymbalariae. Indeed, the production of 2-phenylethanol by A. gossypii was determined to be higher than that in S. cerevisiae strains, namely Weihenstephan lager yeast and laboratorial CEN.PK2 (Ravasio et al., 2014). A. gossypii single mutants for the $A R O$ genes revealed a strong impairment in the production of 2-phenylethanol and also isoamyl alcohol (with exception for the AgARO8a) (Ravasio et al., 2014). As AgARO80 encodes a transcriptional regulator of some of these genes, these authors overexpressed this gene. Although it was not possible to note significant differences in the production of 2-phenylethanol (possibly due to phenylalanine limitation in the culture medium), the engineered strain was able to produce about 2.5-fold more isoamyl alcohol and isobutanol than the parent strain (Ravasio et al., 2014). This work reinforced the idea that the exploration of non-Saccharomyces strains for flavour enhancement of fermented beverages may result in a new wide line of products.

Very recently, A. gossypii became the first eukaryotic microorganism presenting good potential for industrial nucleoside production, particularly inosine and guanosine (Ledesma-Amaro et al., 2015). These flavour active compounds (umami flavour) are used by the food industry with various beneficial effects associated to them. Some wild strains have the ability to naturally secrete high levels of inosine and guanosine (Ledesma-Amaro et al., 2015). Furthermore, as a natural riboflavin overproducer, A. gossypii has strong metabolic flow through the purine biosynthetic pathway, the central biosynthetic pathway of these two compounds. Based on this, a series of in silico simulations by the GSMM iRL766 (Ledesma-Amaro et al., 2014b) allowed defining a set of target genes (Table 2) for disruption or overexpression in order to redirect the flux through inosine and/or guanosine biosynthesis. An engineered strain (overexpressing a deregulated $A g A D E 4$; Jiménez et al., 2005) with increased flux through the purine biosynthetic pathway, which served before to enhance riboflavin production, was used as background strain to introduce more specific metabolic shifts (Ledesma-Amaro et al., 2015). From a total of eight new engineered strains, the strain deleted for AgADE12, encoding the enzyme responsible for the conversion of inosine-5'-phosphate (IMP) into adenylosuccinate (sAMP), and for AgPNP1, encoding the enzyme responsible for the conversion of the nucleosides (inosine and guanosine) into nucleobases (hypoxanthine and guanine), was able to produce and excrete 24-fold more inosine $(0.27 \mathrm{~g} / \mathrm{L})$ and 2 -fold more guanosine $(0.14 \mathrm{~g} / \mathrm{L})$ than the wild type strain (Ledesma-Amaro et al., 2015).

The filamentous fungus $A$. gossypii demonstrated once again to possess a very interesting natural potential and the machinery needed to create improved engineered strains for different biotechnological applications, in this particular case as a natural flavour producer for the fermented beverages and food industries. The advent of systems biology has allowed leveraging this natural biotechnological potential of A. gossypii (Ledesma-Amaro et al., 2015) and will continue playing a major role in the development of this fungus as a cell factory.

With a dominant position in what concerns industrial riboflavin production, A. gossypii has beneficiated from constant and sustainable improvement of its natural ability, thus keeping the commercial competitiveness of the process. Production of riboflavin by A. gossypii will always be a landmark for the White Biotechnology and its improvement will continue to be pursued. However, there is no doubt that the trend in the last years show that $A$. gossypii holds the potential to expand its biotechnological significance way beyond riboflavin production. Following the promising results obtained with the production of recombinant proteins, SCOs and flavour compounds, future studies should assess if the optimization, scale-up and intensification of these bioprocesses can support the obtainment of economically 
sustainable product yields. On the other hand, further strain engineering should also focus on expanding the range of substrate utilization by this fungus and address the utilization of low-cost substrates derived from renewable raw materials in the abovementioned bioprocesses.

\section{Conclusions}

The filamentous fungus $A$. gossypii has long been exploited for the industrial production of riboflavin. The fruitful synergy resulting from the strong investment in both applied and basic research puts A. gossypii in a leading position in the establishment of the knowledge-based bioeconomy envisaged by the White Biotechnology. The wealth of molecular and in silico tools available for this microorganism has allowed the rational exploitation of its full biotechnological potential, which nowadays goes far beyond the production of riboflavin. It is now time to take advantage of all the knowledge acquired during these years and go further in the search for new commercially valuable applications for this emerging cell factory, such as the recently reported production of recombinant proteins, single cell oil and flavour compounds. To drive these new A. gossypii applications through the successful commercial track of riboflavin production, newer and more flexible tools for its rational engineering and synthetic biology will necessarily have to be combined with process development and optimization. Furthermore, given the physiological and genetic heterogeneity observed between A. gossypii strains, future exploration of this fungus natural biodiversity holds the potential to unravel new strains for the industrial applications described above or for yet unexplored novel applications.

\section{Acknowledgements}

The authors thank the financial support from the Fundação para a Ciência e a Tecnologia (FCT), Portugal, through the Strategic Project of UID/BIO/04469/2013 unit (Post-Doc fellowship UMINHO/BPD/ $36 / 2015$ to T. Q. Aguiar), the project RECI/BBB-EBI/0179/2012 (FCOMP-01-0124-FEDER-027462) and the project "BioInd - Biotechnology and Bioengineering for improved Industrial and Agro-Food processes", REF. NORTE-07-0124-FEDER-000028, co-funded by the Programa Operacional Regional do Norte (ON.2 - O Novo Norte), QREN, FEDER.

\section{References}

Aguiar, T.Q., Dinis, C., Domingues, L., 2014c. Cre-loxP-based system for removal and reuse of selection markers in Ashbya gossypii targeted engineering. Fungal Genet. Biol. 68 $1-8$.

Aguiar, T.Q., Dinis, C., Magalhães, F., Oliveira, C., Wiebe, M.G., Penttilä, M., et al., 2014b. Molecular and functional characterization of an invertase secreted by Ashbya gossypii. Mol. Biotechnol. 56, 524-534.

Aguiar, T.Q., Maaheimo, H., Heiskanen, A., Wiebe, M.G., Penttilä, M., Domingues, L., 2013. Characterization of the Ashbya gossypii secreted N-glycome and genomic insights into its N-glycosylation pathway. Carbohydr. Res. 381, 19-27.

Aguiar, T.Q., Ribeiro, O., Arvas, M., Wiebe, M.G., Penttilä, M., Domingues, L., 2014a. Investigation of protein secretion and secretion stress in Ashbya gossypii. BMC Genomics $15,1137$.

Alberti-Segui, C., Dietrich, F., Altmann-Jöhl, R., Hoepfner, D., Phillipsen, P., 2001. Cytoplasmic dynein is required to oppose the force that moves nuclei towards the hyphal tip in the filamentous ascomycete Ashbya gossypii. J. Cell Sci. 114, 975-986.

Althöefer H., Revuelta J.L., Genetic strain optimization for improving the production of riboflavin. WO Patent No. 2003/048367 A1.

Althöefer H., Pompeus M., Revuelta J.L., Santos M., Jiminez A., Benito R., et al., Protein production using Ashbya gossypii. WO Patent No. 2001/023576

Althöefer H., Revuelta J.L., Seulberg H., Zelder O., Genetic method for producing riboflavin. WO Patent No. 1999/061623 A2.

Altmann-Jöhl, R., Philippsen, P., 1996. AgTHR4, a new selection marker for transformation of the filamentous fungus Ashbya gossypii, maps in a four-gene cluster that is conserved between A. gossypii and Saccharomyces cerevisiae. Mol. Gen. Genet. 250, 69-80.

Anderson, C.A., Roberts, S., Zhang, H., Kelly, C.M., Kendall, A., Lee, C.H., et al., 2015. Ploidy variation in multinucleate cells changes under stress. Mol. Biol. Cell 26, 1129-1140.

Ashby, S.F., Nowell, W., 1926. The fungi of stigmatomycosis. Ann. Bot. 40, 69-84.

Ayad-Durieux, Y., Knechtle, P., Goff, S., Dietrich, F., Philippsen, P., 2000. A PAK-like kinase is required for maturation of young hyphae and septation in the filamentous ascomycete Ashbya gossypii. J. Cell Sci. 113, 4563-4575.
Batra, L.R., 1973. Nematosporaceae (Hemiascomycetidae): taxonomy, pathogenicity, distribution, and vector relations. US Dep. Agric. Tech. Bull. 1469, 1-71.

Beopoulos, A., Nicaud, J., Gaillardin, C., 2011. An overview of lipid metabolism in yeasts and its impact on biotechnological processes. Appl. Microbiol. Biotechnol. 90, 1193-1206.

Brachat, S., Dietrich, F.S., Voegeli, S., Zhang, Z., Stuart, L., Lerch, A., et al., 2003. Reinvestigation of the Saccharomyces cerevisiae genome annotation by comparison to the genome of a related fungus: Ashbya gossypii. Genome Biol. 4, R45.

Buston, H.W., Kasinathan, S., 1933. The accessory factor necessary for the growth of Nematospora gossypii. III. The preparation of concentrates of the second accessory factor. Biochem. J. 27, 1859-1868.

Buston, H.W., Pramanik, N.B., 1931. The accessory factor necessary for the growth of Nematospora gossypii. The chemical nature of the accessory factor. Biochem. J. 25, 1656-1670.

Buston, H.W., Kasinathan, S., Wylie, S.M., 1938. The nitrogen requirements of Nematospora gossypii in synthetic media. Ann. Bot. 2, 373-379.

Caskey, C., Gallup, W.D., 1931. Changes in the sugar, oil and gossypol content of the developing cotton boll. J. Agric. Res. 42, 671-673.

Dammer, K.H., Ravelo, H.G., 1990. Verseuchung von Leptoglossus gonagra (Fabr.) mit Nematospora coryli Peglion und Ashbya gossypii (Ashby et Nowell) Guilliermond in einer zitrusanlage der Republik Kuba. Arch Phytopathol Pflanzenschutz Berlin 26, 71-78.

Demain, A.L., 1972. Riboflavin oversynthesis. Annu. Rev. Microbiol. 26, 369-388.

Demain, A.L., Vaishnav, P., 2009. Production of recombinant proteins by microbes and higher organisms. Biotechnol. Adv. 27, 297-306.

DiCarlo, J.E., Norville, J.E., Mali, P., Rios, X., Aach, J., Church, G.M., 2013. Genome engineering in Saccharomyces cerevisiae using CRISPR-Cas systems. Nucleic Acids Res. 41, 4336-4343.

Dietrich, F.S., Voegeli, S., Brachat, S., Lerch, A., Gates, K., Steiner, S., et al., 2004. The Ashbya gossypii genome as a tool for mapping the ancient Saccharomyces cerevisiae genome. Science 304, 304-307.

Dietrich, F.S., Voegelli, S., Kuo, S., Philippsen, P., 2013. Genomes of Ashbya fungi isolated from insects reveal four mating-type loci, numerous translocations, lack of transposons, and distinct gene duplications. G3 (Bethesda). 3, pp. 1225-1239.

Domingues, L., Lima, N., Teixeira, J.A., 2005. Aspergillus niger $\beta$-galactosidase production by yeast in a continuous high cell density reactor. Process Biochem. 40, 1151-1154.

Domingues, L., Teixeira, J.A., Penttilä, M., Lima, N., 2002. Construction of a flocculent Saccharomyces cerevisiae strain secreting high levels of Aspergillus niger $\beta$ galactosidase. Appl. Microbiol. Biotechnol. 58, 645-650.

Domizio, P., Romani, C., Lencioni, L., Comitini, F., Gobbi, M., Mannazu, I., et al., 2010. Outlining a future for non-Saccharomyces yeasts: selection of putative spoilage wine strains to be used in association with Saccharomyces cerevisiae for grape juice fermentation. Int. J. Food Microbiol. 147, 170-180.

Dünkler, A., Wendland, J., 2007. Use of MET3 promoters for regulated gene expression in Ashbya gossypii. Curr. Genet. 52, 1-10.

Farries, E.H.M., Bell, A.F., 1930. On the metabolism of Nematospora gossypii and related fungi, with special reference to the source of nitrogen. Ann. Bot. 44, 423-455.

Fitzpatrick, D.A., Logue, M.E., Stajich, J.E., Butler, G., 2006. A fungal phylogeny based on 42 complete genomes derived from supertree and combined gene analysis. BMC Evol. Biol. 6, 99.

Förster, C., Marienfeld, S., Wendisch, V.F., Krämer, R., 1998. Adaptation of the filamentous fungus Ashbya gossypii to hyperosmotic stress: different osmoresponse to $\mathrm{NaCl}$ and mannitol stress. Appl. Microbiol. Biotechnol. 50, 219-226.

Förster, C., Santos, M., Ruffert, S., Krämer, R., Revuelta, J.L., 1999. Physiological consequence of disruption of the VMA1 gene in the riboflavin overproducer Ashbya gossypii. J. Biol. Chem. 274, 9442-9448.

Fragoso, R.G., Ciferri, R., 1928. Hongos parasitos y saprifitos de la Republica Dominicana. Bol. R. Soc. Esp. Hist. Nat. 28, 377-388.

Gladfelter, A.S., Hungerbuehler, A.K., Philippsen, P., 2006. Asynchronous nuclear division cycles in multinucleated cells. J. Cell Biol. 3, 347-362.

Gomes, D., Aguiar, T.Q., Dias, O., Ferreira, E.C., Domingues, L., Rocha, I., 2014. Genome wide metabolic re-annotation of Ashbya gossypii: new insights into its metabolism through a comparative analysis with Saccharomyces cerevisiae and Kluyveromyces lactis. BMC Genomics 15, 810.

Goodman, J.J., Ferrera, R.R., 1954. Synthesis of riboflavin by Ashbya gossypii grown in a synthetic medium. Mycologia 46, 556.

Grünler, A., Walther, A., Lämmel, J., Wendland, J., 2010. Analysis of flocculins in Ashbya gossypii reveals FIG2 regulation by TEC1. Fungal Genet. Biol. 47, 619-628.

Guilliermond, A., 1928. Recherches sur quelques Ascomycetes inferieurs isoles de la Stigmatomycose des graines de Cotonnier. Essai sur la phylogenie des Ascomycetes. Rev. Gen. Bot. 40, 328-342 (397-414; 474-85; 555-74; 606-24; 690-704).

Hashimoto, K., Yoshizawa, A.C., Okuda, S., Kuma, K., Goto, S., Kanehisa, M., 2008. The repertoire of desaturases and elongases reveals fatty acid variations in 56 eukaryotic genomes. J. Lipid Res. 49, 183-191.

Jiménez, A., Santos, M.A., Pompejus, M., Revuelta, J.L., 2005. Metabolic engineering of the purine pathway for riboflavin production in Ashbya gossypii. Appl. Environ. Microbiol. $71,5743-5751$.

Jiménez, A., Santos, M.A., Revuelta, J.L., 2008. Phosphoribosyl pyrophosphate synthetase activity affects growth and riboflavin production in Ashbya gossypii. BMC Biotechnol. 8, 67-78.

Karos, M., Vilariño, C., Bollschweiler, C., Revuelta, J.L., 2004. A genome-wide transcription analysis of a fungal riboflavin overproducer. J. Biotechnol. 113, 69-76.

Käsler B., Sahm H., Stahmann K.P., Schmidt G., Boeddecker B., Seulberger H., Riboflavinproduction process by means of microorganisms with modified isocitrate lyase activity. WO Patent No. 1997/03208 A 
Kato, T., Park, E.Y., 2006. Expression of alanine:glyoxylate aminotransferase gene from Saccharomyces cerevisiae in Ashbya gossypii. Appl. Microbiol. Biotechnol. 71, 46-52.

Kato, T., Park, E.Y., 2012. Riboflavin production by Ashbya gossypii. Biotechnol. Lett. 34 611-618.

Kaufmann, A., Philippsen, P., 2009. Of bars and rings: Hof1-dependent cytokinesis in multiseptated hyphae of Ashbya gossypii. Mol. Cell. Biol. 29, 771-783.

Kaufmann, A., 2009. A plasmid collection for PCR-based gene targeting in the filamentous ascomycete Ashbya gossypii. Fungal Genet. Biol. 46, 595-603.

Kavitha, S., Chandra, T.S., 2009. Effect of vitamin E and menadione supplementation on riboflavin production and stress parameters in Ashbya gossypii. Process Biochem. 44, 934-938.

Kavitha, S., Chandra, T.S., 2014. Oxidative stress protection and glutathione metabolism in response to hydrogen peroxide and menadione in riboflavinogenic fungus Ashbya gossypii. Appl. Biochem. Biotechnol. 174, 2307-2325.

Knechtle, P., Dietrich, F., Philippsen, P., 2003. Maximal polar growth potential depends on the polarisome component AgSpa2 in the filamentous fungus Ashbya gossypii. Mol. Biol. Cell 14, 4140-4154.

Kögl, F., Fries, N., 1937. Uber den einfluss von biotin, aneurin, und meso-inosit auf das Wachstum verschiedenen Pilzarten. 26. Mitteil-ung iiber pflanzliche wachstumstoffe. Ztschr. Physiol. Chem. 249, 93-110.

Köhli, M., Galati, V., Boudier, K., Roberson, R.W., Philippsen, P., 2008. Growth-speedcorrelated localization of exocyst and polarisome components in growth zones of Ashbya gossypii hyphal tips. J. Cell Sci. 121, 3878-3889.

Kruger, N.J., von Schaewen, A., 2003. The oxidative pentose phosphate pathway: structure and organisation. Curr. Opin. Plant Biol. 6, 236-246.

Kurtzman, C.P., 1995. Relationships among the genera Ashbya, Eremothecium, Holleya, and Nematospora determined from rDNA sequence divergence. J. Ind. Microbiol. 14, 523-530.

Kurtzman, C.P., Robnett, C.J., 2003. Phylogenetic relationships among yeasts of the 'Saccharomyces complex' determined from multigene sequence analyses. FEMS Yeast Res. 3, 417-432.

Kutsal, T., Özbas, M.T., 1989. Microbial production of vitamin B2 (riboflavin). In: Vandamme, E.J. (Ed.), Biotechnology of Vitamins, Pigments and Growth Factors. Elsevier, London, pp. 149-166.

Ledesma-Amaro, R., Kerkhoven, E.J., Revuelta, J.L., Nielsen, J., 2014b. Genome scale metabolic modeling of the riboflavin overproducer Ashbya gossypii. Biotechnol. Bioeng. 111, 1191-1199.

Ledesma-Amaro, R., Santos, M.A., Jiménez, A., Revuelta, J.L., 2014a. Strain design of Ashbya gossypii for single-cell oil production. Appl. Environ. Microbiol. 80, 1237-1244.

Ledesma-Amaro, R., Santos, M.A., Jiménez, A., Revuelta, J.L., 2014c. Tuning single-cell oil production in Ashbya gossypii by engineering the elongation and desaturation systems. Biotechnol. Bioeng. 111, 1782-1791.

Ledesma-Amaro, R., Buey, R.M., Revuelta, J.L., 2015. Increased production of inosine and guanosine by means of metabolic engineering of the purine pathway in Ashbya gossypii. Microb. Cell Factories 14, 58.

Lim, S.H., Choi, J.S., Park, E.Y., 2001. Microbial production of riboflavin using riboflavin overproducers, Ashbya gossypii, Bacillus subtilis, and Candida famate: an overview. Biotechnol. Bioprocess Eng. 6, 75-88.

Lizama, G., Moguel-Salazar, F., Peraza-Luna, F., Ortiz-Vázquez, E., 2007. Riboflavin production from mutants of Ashbya gossypii utilising orange rind as a substrate. Ann. Microbiol. 57, 157-161.

Maeting, I., Schmidt, G., Sahm, H., Revuelta, J.L., Stierhofd, Y.D., Stahmanna, K.P., 1999. Isocitrate lyase of Ashbya gossypii - transcriptional regulation and peroxisomal localization. FEBS Lett. 444, 15-21.

Maeting, I., Schmidt, G., Sahm, H., Stahmanna, K.P., 2000. Role of a peroxisomal NADPspecific isocitrate dehydrogenase in the metabolism of the riboflavin overproducer Ashbya gossypii. J. Mol. Catal. B Enzym. 10, 335-343.

Magalhães, F., Aguiar, T.Q., Oliveira, C., Domingues, L., 2014. High-level expression of Aspergillus niger $\beta$-galactosidase in Ashbya gossypii. Biotechnol. Prog. 30, 261-268.

Mateos, L., Jiménez, A., Revuelta, J., Santos, M., 2006. Purine biosynthesis, riboflavin production, and trophic phase span are controlled by a Myb-related transcription factor in the fungus Ashbya gossypii. Appl. Environ. Microbiol. 72, 5052-5060.

Mickelson, M.N., 1950. The metabolism of glucose by Ashbya gossypii. J. Bacteriol. 59, 559-566.

Mickelson, M.N., Schuler, M.N., 1953. Oxidation of acetate by Ashbya gossypii. J. Bacteriol. 65, 297-304.

Monschau, N., Sahm, H., Stahmann, K.P., 1998. Threonine aldolase overexpression plus threonine supplementation enhanced riboflavin production in Ashbya gossypii. Appl. Environ. Microbiol. 64, 4283-4290.

Nieland, S., Stahmann, K.P., 2013. A developmental stage of hyphal cells shows riboflavin overproduction instead of sporulation in Ashbya gossypii. Appl. Microbiol. Biotechnol. 97, 10143-10153.

Nikolaou, E., Agrafioti, I., Stumpf, M., Quinn, J., Stansfield, I., Brown, A.J.P., 2009. Phylogenetic diversity of stress signalling pathways in fungi. BMC Evol. Biol. 9, 44.

Oliveira, C., Teixeira, J.A., Lima, N., Da Silva, N., Domingues, L., 2007. Development of a stable flocculent Saccharomyces cerevisiae strain for continuous Aspergillus niger $\beta$ galactosidase production. J. Biosci. Bioeng. 103, 318-324.

Özbas, M.T., Kutsal, T., 1986. Comparative study of riboflavin production from two microorganisms: Eremothecium ashbyi and Ashbya gossypii. Enzym. Microb. Technol. 8, 593-596.

Park, E.Y., Ito, Y., Nariyama, M., Sugimoto, T., Lies, D., Kato, T., 2011. The improvement of riboflavin production in Ashbya gossypii via disparity mutagenesis and DNA microarray analysis. Appl. Microbiol. Biotechnol. 91, 1315-1326.

Park, E.Y., Zhang, J.H., Tajima, S., Dwiarti, L., 2007. Isolation of Ashbya gossypii mutant for an improved riboflavin production targeting for biorefinery technology. J. Appl. Microbiol. 103, 468-476.
Perez-Nadales, E., Nogueira, M.F.A., Baldin, C., Castanheira, S., El Ghalid, M., Grund, E., 2014. Fungal model systems and the elucidation of pathogenicity determinants. Fungal Genet. Biol. 70, 42-67.

Perlman, D., 1979. Microbial process for riboflavin production. In: Pepplev, H.J., Pevlman, D. (Eds.), Microbial Technology. Academic Press, New York, pp. 521-527.

Pfeifer, V.F., Tanner, F.W., Vojnovich, C., Traufler, D.H., 1950. Riboflavin by fermentation with Ashbya gossypii. Ind. Eng. Chem. 42, 1776-1781.

Pompejus M., Revuelta J.L., Santos M.A., Orotidine-5'-phosphate decarboxylase-gene, gene construct containing said gene and the utilization thereof. WO Patent No. 1999/036432.

Pridham, T.G., Raper, K.B., 1950. Ashbya gossypii - its significance in nature and in the laboratory. Mycologia 42, 603-623.

Pridham, T.G., Raper, K.B., 1952. Studies on variation and mutation in Ashbya gossypii. Mycologia 44, 452-469.

Prillinger, H., Schweigkofler, W., Breitenbach, M., Briza, P., Staudacher, E., Lopandic, K., et al., 1997. Phytopathogenic filamentous (Ashbya, Eremothecium) and dimorphic fung (Holleya, Nematospora) with needle-shaped ascospores as new members within the Saccharomycetaceae. Yeast 13, 945-960.

Ramakrishnan, S., Hartley, B.S., 1993. Fermentation of lactose by yeast cells secreting recombinant fungal lactase. Appl. Environ. Microbiol. 59, 4230-4235.

Ravasio, D., Wendland, J., Walther, A., 2014. Major contribution of the Ehrlich pathway for 2-phenylethanol/rose flavor production in Ashbya gossypii. FEMS Yeast Res. 14, 833-844.

Read, N.D., 2011. Exocytosis and growth do not occur only at hyphal tips. Mol. Microbiol. 81, 4-7.

Revuelta J.L., Santos M.A., Pompejus M., Seulberger H., Promoter from Ashbya gossypii. WO Patent No. 1999/033993.

Ribeiro, O., Domingues, L., Penttilä, M., Wiebe, M.G., 2012. Nutritional requirements and strain heterogeneity in Ashbya gossypii. J. Basic Microbiol. 52, 582-589.

Ribeiro, O., Magalhães, F., Aguiar, T.Q., Wiebe, M.G., Penttilä, M., Domingues, L., 2013. Random and direct mutagenesis to enhance protein secretion in Ashbya gossypii. Bioengineering 4, 1-10.

Ribeiro, O., Wiebe, M., Ilmén, M., Domingues, L., Penttilä, M., 2010. Expression of Trichoderma reesei cellulases CBHI and EGI in Ashbya gossypii. Appl. Microbiol. Biotechnol. 87, 1437-1446.

Santos, M.A., Mateos, L., Stahmann, K.P., Revuelta, J.L., 2005. Insertional mutagenesis in the vitamin $B_{2}$ producer fungus Ashbya gossypii. Methods Biotechnol. 18, 283-300.

Schade, D., Walther, A., Wendland, J., 2003. The development of a transformation system for the dimorphic plant pathogen Holleya sinecauda based on Ashbya gossypii DNA elements. Fungal Genet. Biol. 40, 65-71.

Schlösser, T., Schmidt, G., Stahmann, K.P., 2001. Transcriptional regulation of 3,4-dihydroxy-2-butanone 4-phosphate synthase. Microbiology 147, 3377-3386.

Schlösser, T., Wiesenburg, A., Gätgens, C., Funke, A., Viets, U., Vijayalakshmi, S., et al., 2007. Growth stress triggers riboflavin overproduction in Ashbya gossypii. Appl. Microbiol. Biotechnol. 76, 569-578.

Schlüpen, C., Santos, M.A., Weber, U., De Graaf, A., Revuelta, J.L., Stahmann, K.P., 2003. Disruption of the SHM2 gene, encoding one of two serine hydroxymethyltransferase isozymes, reduces the flux from glycine to serine in Ashbya gossypii. Biochem. J. 369 263-273.

Schmidt, G., Stahmann, K.P., Sahm, H., 1996b. Inhibition of purified isocitrate lyase identified itaconate and oxalate as potential antimetabolites for the riboflavin overproducer Ashbya gossypii. Microbiology 142, 411-417.

Schmidt, G., Stahmann, K.P., Kaesler, B., Sahm, H., 1996a. Correlation of isocitrate lyase activity and riboflavin formation in the riboflavin overproducer Ashbya gossypii. Microbiology 142, 419-426.

Schmitz, H.P., Philippsen, P., 2011. Evolution of multinucleated Ashbya gossypii hyphae from a budding yeast-like ancestor. Fungal Biol. 115, 557-568.

Silva, R., Aguiar, T.Q., Domingues, L., 2015. Blockage of the pyrimidine biosynthetic pathway affects riboflavin production in Ashbya gossypii. J. Biotechnol. 193, 37-40.

Smiley, K.L., Sobolov, M., Austin, F.L., Rasmussen, R.A., Smith, M.B., van Lanen, J.M., et al. 1951. Biosynthesis of riboflavin, L. bulgaricus factor, and other growth factors. Laboratory and pilot plant studies of biosynthesis by A. gossypii cultivated on grain stillage media. Ind. Eng. Chem. 43, 1380-1384.

Stahmann, K.P., Arst Jr., H.N., Althöfer, H., Revuelta, J.L., Monschau, N., Schlüpen, C., et al. 2001. Riboflavin, overproduced during sporulation of Ashbya gossypii, protects its hyaline spores against ultraviolet light. Environ. Microbiol. 3, 545-550.

Stahmann, K.P., Böddecker, T., Sahm, H., 1997. Regulation and properties of a fungal lipase showing interfacial inactivation by gas bubbles, or droplets of lipid or fatty acid. Eur. J. Biochem. 244, 220-225.

Stahmann, K.P., Kupp, C., Feldmann, S.D., Sahm, H., 1994. Formation and degradation of lipid bodies found in the riboflavin-producing fungus Ashbya gossypii. Appl Microbiol. Biotechnol. 42, 121-127.

Stahmann, K.P., Revuelta, J.L., Suelberger, H., 2000. Three biotechnical process using Ashbya gossypii, Candida famata, or Bacillus subtilis compete with chemical riboflavin production. Appl. Microbiol. Biotechnol. 53, 509-516.

Steiner, S., Philippsen, P., 1994. Sequence and promoter analysis of the highly expressed TEF gene of the filamentous fungus Ashbya gossypii. Mol. Gen. Genet. 242, 263-271.

Steiner, S., Wendland, J., Wright, M.C., Philippsen, P., 1995. Homologous recombination as the main mechanism for DNA integration and cause of rearrangements in the filamentous ascomycete Ashbya gossypii. Genetics 140, 973-987.

Sugimoto, T., Kanamasa, S., Kato, T., Park, E.Y., 2009. Importance of malate synthase in the glyoxylate cycle of Ashbya gossypii for the efficient production of riboflavin. Appl. Microbiol. Biotechnol. 83, 529-539.

Sugimoto, T., Kato, T., Park, E.Y., 2014. Functional analysis of cis-aconitate decarboxylase and trans-aconitate metabolism in riboflavin-producing filamentous Ashbya gossypii. J. Biosci. Bioeng. 117, 563-568. 
Sugimoto, T., Morimoto, A., Nariyama, M., Kato, T., Park, E.Y., 2010. Isolation of an oxalateresistant Ashbya gossypii strain and its improved riboflavin production. J. Ind. Microbiol. Biotechnol. 37, 57-64.

Tajima, S., Itoh, Y., Sugimoto, T., Kato, T., Park, E.Y., 2009. Increased riboflavin production from activated bleaching earth by a mutant strain of Ashbya gossypii. J. Biosci. Bioeng. 108, 325-329.

Tanner Jr., F.W., Vojnovich, C., Van Lanen, J.M., 1949. Factors affecting riboflavin production by Ashbya gossypii. J. Bacteriol. 58, 737-745.

von Arx, J.A., van der Walt, J.P., 1987. Ophiostomatales and endomycetales. Stud. Mycol. 30, 167-176.

Vorapreeda, T., Chinae Thammarongtham, C., Cheevadhanarak, S., Laoteng, K., 2012. Alternative routes of acetyl-CoA synthesis identified by comparative genomic analysis: involvement in the lipid production of oleaginous yeast and fungi. Microbiology $158,217-228$.

Walther, A., Wendland, J., 2004. Apical localization of actin patches and vacuolar dynamics in Ashbya gossypii depend on the WASP homolog Wal1p. J. Cell Sci. 117, 4947-4958.

Walther, A., Wendland, J., 2012. Yap1-dependent oxidative stress response provides a link to riboflavin production in Ashbya gossypii. Fungal Genet. Biol. 49, 697-707.

Wang, H., Xu, Z., Gao, L., Hao, B., 2009. A fungal phylogeny based on 82 complete genomes using the composition vector method. BMC Evol. Biol. 9, 195.

Wasserstrom, L., Lengeler, K., Walther, A., Wendland, J., 2015. Developmental growth control exerted via the A kinase Tpk2 in Ashbya gossypii. Eukaryot. Cell 14, 593-601.

Wasserstrom, L., Lengeler, K.B., Walther, A., Wendland, J., 2013. Molecular determinants of sporulation in Ashbya gossypii. Genetics 195, 87-99.

Wei, S., Hurley, J., Jiang, Z., Wang, S., Wang, Y., 2012. Isolation and characterization of an Ashbya gossypii mutant for improved riboflavin production. Braz. J. Microbiol. 441-448.
Wei, S., Zheng, W., Zhao, F., Jiang, Z., Zhou, D., 2013. Microbial conversion of waste cooking oil into riboflavin by Ashbya gossypii. Biosci. J. 29, 1000-1006.

Wendland, J., Philippsen, P., 2000. Determination of cell polarity in germinated spores and hyphal tips of the filamentous ascomycete Ashbya gossypii requires a rhoGAP homolog. J. Cell Sci. 113, 1611-1621.

Wendland, J., Philippsen, P., 2001. Cell polarity and hyphal morphogenesis are controlled by multiple Rho-protein modules in the filamentous ascomycete Ashbya gossypii. Genetics 157, 601-610.

Wendland, J., Walther, A., 2005. Ashbya gossypii: a model for fungal developmental biology. Nat. Rev. Microbiol. 3, 421-429.

Wendland, J., Walther, A., 2011. Genome evolution in the Eremothecium clade of the Saccharomyces complex revealed by comparative genomics. G3 (Bethesda). 1, pp. 539-548.

Wendland, J., Walther, A., 2014. Chromosome number reduction in Eremothecium coryli by two telomere-to-telomere fusions. Genome Biol. Evol. 6, 1186-1198.

Wendland, J., Ayad-Durieux, Y., Knechtle, P., Rebischung, C., Philippsen, P., 2000. PCRbased gene targeting in the filamentous fungus Ashbya gossypii. Gene 242, 381-391.

Wendland, J., Dünkler, A., Walther, A., 2011. Characterization of $\alpha$-factor pheromone and pheromonereceptor genes of Ashbya gossypii. FEMS Yeast Res. 11, 418-429.

Wickerham, L.S., Flickinger, M.H., Johnston, R.M., 1946. Production of riboflavin by Ashbya gossypii. Arch. Biochem. 9, 95-98.

Wright, M.C., Philippsen, P., 1991. Replicative transformation of the filamentous fungus Ashbya gossypii with plasmids containing Saccharomyces cerevisiae ARS elements. Gene 109, 99-105.

zu Berstenhorst, S.M., Hohmann, H.P., Stahmann, K.P., 2009. Vitamins and vitamin-like compounds: microbial production. In: Schaechter, M. (Ed.), Encyclopedia of Microbiology. Academic Press, Oxford, pp. 549-561. 